\title{
REPRESENTAÇÕES SOCIAIS SOBRE A PROFISSÃO DE EDUCAÇÃO FÍSICA: UM OLHAR PARA A LITERATURA ${ }^{1}$
}

\section{ESTADO DA ARTE}

ANTUNES, Alfredo Cesar ${ }^{2}$

CASTRO, Ricardo Vieiralves de ${ }^{3}$

ANTUNES, Alfredo Cesar. CASTRO, Ricardo Vieiralves de. Representações sociais sobre a profissão de Educação Física: Um olhar para a literatura. Revista Científica Multidisciplinar Núcleo do Conhecimento. Ano 05, Ed. 11, Vol. 19, pp. 2554. Novembro de 2020. ISSN: 2448-0959, Link de acesso: https://www.nucleodoconhecimento.com.br/educacao-fisica/representacoessociais

\section{RESUMO}

O objetivo do presente estudo foi compreender a produção de conhecimento sobre a profissão de Educação Física, sob a perspectiva da Teoria das Representações Sociais. Para a realização do estudo foram seguidas 2 etapas. A primeira foi a busca no Catálogo de Teses e Dissertações da CAPES. Na segunda etapa foi realizada a busca por artigos no Portal de Periódicos da CAPES. De acordo com os critérios de inclusão e exclusão, determinados na metodologia, foram identificadas e analisadas

\footnotetext{
${ }_{1}^{1}$ Artigo elaborado com dados coletados para a pesquisa de pós-doutorado realizado na UERJ, no programa de Psicologia Social e com apoio da Fundação Araucária de Apoio ao Desenvolvimento Científico e Tecnológico do Estado do Paraná (FA), por meio do Programa de Bolsa de Pós-Doutorado.

2 Doutorado em Ciência do Desporto. Mestrado em Ciências da Motricidade. Graduação em Educação Física.

3 Doutorado em Comunicação. Mestrado em Psicologia (Psicologia Clínica). Aperfeiçoamento em Teoria dos Sonhos. Graduação em Psicologia.
} 
doze (12) pesquisas sobre o objeto investigado, entre artigos, dissertações e teses. Identificou-se como características da produção acadêmica baixa frequência de estudos relacionados às RS sobre a profissão de EF, diversidade de campos de atuação e sujeitos diversos e predomínio de entrevistas e questionários para a coleta de informações. Os aspectos mais evidentes da produção acadêmico sobre a profissão de Educação Física foram as críticas à formação acadêmica, desvalorização profissional (autodesvalorização) em contraste com a valorização por outros segmentos sociais, preocupação com a postura/conduta profissional, preconceitos contra grupos específicos e diversidade de objetivos e funções da atividade profissional. Conclui-se que, a perspectiva apresentada pelas pesquisas analisadas permite uma interpretação mais ampliada da Educação Física como um fenômeno social, no sentido de identificar aspectos marcantes e que ficam em evidência nas RS sobre a profissão.

Palavras-chave: educação física, representações sociais, profissão, estado do conhecimento.

\section{INTRODUÇÃO}

O objetivo do presente estudo foi compreender o estado do conhecimento sobre a profissão de Educação Física, sob a perspectiva da Teoria das Representações Sociais (TRS) com base Moscoviciana, com o intuito de entender como está sendo tratada e investigada.

A área de Representações Sociais mostra-se atualmente como uma sólida teoria que possibilita a análise e interpretação de nossa sociedade, com base nas construções discursivas dos sujeitos em seu cotidiano. O seu principal autor e teórico, Serge Moscovici (2013), apresenta a teoria a partir de uma perspectiva que transcende a visão estática das representações coletivas desenhadas por Durkheim $(1971,2015)$.

A compreensão do não-familiar pelos sujeitos é o ponto chave da construção das RS. Transformar um conceito em imagem (objetivação) e organizar e relacionar estes novos conhecimentos, com base em categorias já conhecidas pelo sujeito 
(ancoragem) é fundamental para esse processo de compreensão e adaptação. Esse processo acontece como forma de proteção ao sofrimento pelo desconhecido (nãofamiliar), familiarizando os indivíduos de um determinado grupo social ao que é novo.

Entretanto, esse processo não pode ser visto como algo mecânico e sem capacidade de proporcionar transformação e evolução para os indivíduos, até mesmo porque o conhecimento sobre os diferentes fenômenos depende da construção e da interação entre RS dos sujeitos sobre os objetos. Representação sobre representações. Inclusive, pode-se considerar que uma RS é uma representação sobre RS anteriores que foram familiarizadas. O processo apenas permite a evolução de forma acomodada.

Outro aspecto, fundamental, é o seu caráter dinâmico, mas não efêmero. Por isso mesmo, diferente das representações coletivas de Durkheim $(1971,2015)$. Aliás, a nossa sociedade, muito mais veloz, em todos os aspectos, e principalmente na comunicação, exige um processo de construção das representações muito mais dinâmica do que as sociedades totêmicas analisadas por Durkheim.

Também, não se pode confundir RS com as opiniões. Estas fazem parte daquela, mas possuem processos distintos.

Assim, quando o sujeito exprime opinião sobre o objeto, devemos supor que ele já tem representado alguma coisa do objeto, que o estímulo e a resposta são formados juntos. Em suma, a resposta não é uma reação ao estímulo, mas, até certo ponto, sua origem. O estímulo é determinado pela resposta (MOSCOVICI, 2012, p. 45).

As RS estão presentes em nosso cotidiano, fazem parte do nosso processo de comunicação e é um "guia de comportamentos". As RS produzem comportamentos e relações com o ambiente. (MOSCOVICl, 2012).

Desta forma, sendo a Educação Física uma área que se desenvolve por meio das interações e comunicações no cotidiano, especialmente a corporal, construindo RS sobre diversos objetos, entende-se que a TRS pode colaborar na compreensão do seu processo de constituição e desenvolvimento como profissão. 
Assim, procurou-se compreender qual a produção acadêmica sobre a profissão de Educação Física com base no referencial teórico das RS.

\section{PROCEDIMENTO METODOLÓGICO}

O estado do conhecimento permite a compreensão do que está sendo produzido e publicado sobre um determinado assunto, tanto no que se refere aos assuntos específicos quanto às metodologias utilizadas (MOROSINI; FERNANDES, 2014; ROMANOWSKI; ENS, 2006).

Morosini e Fernandes (2014, p. 155) definem estado do conhecimento como

[...] identificação, registro, categorização que levem à reflexão e síntese sobre a produção cientifica de uma determinada área, em um determinado espaço de tempo, congregando periódicos, teses, dissertações e livros sobre uma temática específica. Uma característica a destacar é a sua contribuição para a presença do novo na monografia.

Portanto, é importante destacar que o estado do conhecimento difere do estado da arte. Enquanto o estado da arte abarca tudo o que foi produzido em uma determinada área de conhecimento, ou seja, em teses, dissertações, eventos científicos e artigos, o estado do conhecimento faz uma delimitação das fontes de busca do objeto pesquisado como, por exemplo, apenas teses e dissertações ou apenas artigos em periódicos. (ROMANOWSKI e ENS, 2006). Também, é mais comum nas pesquisas em estado do conhecimento uma delimitação temporal do estudo, como por exemplo, nos últimos cinco ou três anos.

Assim, para a realização do estado do conhecimento foram seguidas 2 etapas. A primeira foi a busca no Catálogo de Teses e Dissertações da CAPES[4]. Na segunda etapa foi realizada a busca por artigos no Portal de Periódicos da CAPES[5].

Para serem incluídas na amostra (critérios de inclusão) as pesquisas deveriam possuir no título, resumo ou palavras-chave relação com o termo Representação(ões) Social(ais) e o seu referencial teórico, baseado na Grande Teoria de Moscovici e suas 
abordagens ou correntes teóricas complementares, conforme apresentado por Sá (1998). Estas abordagens são:

uma mais fiel à teoria original, liderada por Denise Jodelet, em Paris; uma que procura articulá-la com uma perspectiva mais sociológica, liderada por Willem Doise, em Genebra; uma que enfatiza a dimensão cognitivo-estrutural das representações, liderada por Jean-Claude Abric, em Aix-em-Provence. (SÁ, 1998, p. 65).

No primeiro momento realizou-se a busca com os termos "representações sociais" AND profissão (primeiro termo entre aspas e com o operador booleano AND entre os termos). A delimitação temporal foi do ano de 2013 ao ano de 2019 (último ano disponível). Esta delimitação justifica-se pelo fato de somente a partir de 2013 os resumos, palavras-chave e textos completos estarem disponíveis na plataforma. Antes desta data a plataforma disponibiliza somente nome do autor, título do trabalho, data, local/instituição e instituição depositária do trabalho.

Também foram realizadas buscas (terceiro filtro) acrescentando o termo profiss ${ }^{*}$ (com o asterisco para recuperar as palavras com as variações dos sufixos) no lugar de profissão, ampliando a possibilidade de resultados.

Assim, foram selecionadas pesquisas que apresentavam como objeto de estudo representações sociais sobre determinada profissão. Dessa forma, não foram consideradas pesquisas que tinham por objetivo as RS de alguma profissão ou seus profissionais sobre algum objeto, mas sim as RS sobre uma profissão.

Foram identificadas 86 pesquisas relacionadas às RS sobre determinada profissão (primeiro filtro), sendo 53 de mestrado e 33 de doutorado. Porém, foram localizadas somente três (03) pesquisas referentes, especificamente, à RS sobre a profissão de Educação Física, sendo, duas com a profissão docente (mestrado e doutorado) e uma com a de técnico de natação (doutorado). Estas três (03) pesquisas estão incluídas com as demais, porém segue para a identificação no Quadro 1. 
QUADRO 1 - Pesquisas de mestrado e doutorado relacionadas à RS sobre a profissão de Educação Física de 2013 a 2019

\begin{tabular}{|c|c|c|c|c|}
\hline TÍTULO & $\begin{array}{l}\text { AUTORE } \\
\text { S }\end{array}$ & $\begin{array}{l}\text { DADOS DA } \\
\text { PESQUISA }\end{array}$ & $\begin{array}{l}\text { PROFISSÃO } \\
\text { ABORDADA }\end{array}$ & $\begin{array}{l}\text { PALAVRAS- } \\
\text { CHAVE }\end{array}$ \\
\hline $\begin{array}{l}\text { Representações } \\
\text { sociais, docência } \\
\text { e práticas em } \\
\text { educação física } \\
\text { nas escolas } \\
\text { rurais/campo/roç } \\
\text { a do município } \\
\text { de Cunha, SP }\end{array}$ & $\begin{array}{l}\text { Monteiro, } \\
\text { Shirley } \\
\text { Rosane } \\
\text { Aparecida } \\
\text { Fernandes }\end{array}$ & $\begin{array}{l}2016 \\
\text { Mestrado } \\
\text { profissional } \\
\text { em } \\
\text { educação } \\
\text { instituição } \\
\text { de ensino: } \\
\text { Universidad } \\
\text { e de } \\
\text { Taubaté }\end{array}$ & $\begin{array}{l}\text { Profissão docente } \\
\text { - } \\
\text { Docência/educaçã } \\
\text { o física/rural }\end{array}$ & $\begin{array}{l}\text { Educação } \\
\text { física; } \\
\text { educação do } \\
\text { campo; } \\
\text { representações } \\
\text { sociais; } \\
\text { práticas } \\
\text { pedagógicas. }\end{array}$ \\
\hline $\begin{array}{l}\text { As } \\
\text { representações } \\
\text { sociais dos } \\
\text { acadêmicos do } \\
\text { curso de } \\
\text { licenciatura em } \\
\text { educação física } \\
\text { sobre o que é ser } \\
\text { professor }\end{array}$ & $\begin{array}{l}\text { Honorato, } \\
\text { Ilma Celia } \\
\text { Ribeiro. }\end{array}$ & $\begin{array}{l}2017 \\
\text { Doutorado } \\
\text { em } \\
\text { educação } \\
\text { instituição } \\
\text { de ensino: } \\
\text { Universidad } \\
\text { e Estadual } \\
\text { de Ponta } \\
\text { Grossa }\end{array}$ & $\begin{array}{l}\text { Profissão docente } \\
\text { - } \\
\text { Docência/educaçã } \\
\text { o física }\end{array}$ & $\begin{array}{l}\text { Teoria das } \\
\text { representações } \\
\text { sociais; } \\
\text { licenciatura em } \\
\text { educação } \\
\text { física; } \\
\text { formação do } \\
\text { professor de } \\
\text { educação } \\
\text { física; } \\
\text { acadêmicos. }\end{array}$ \\
\hline $\begin{array}{l}\text { O mundo à beira } \\
\text { da piscina: as } \\
\text { representações }\end{array}$ & $\begin{array}{l}\text { Silva, } \\
\text { Morgana } \\
\text { Claudia }\end{array}$ & 2017 & $\begin{array}{l}\text { Técnicos } \\
\text { natação }\end{array}$ & $\begin{array}{l}\text { Técnicos de } \\
\text { natação; } \\
\text { Representaçõe }\end{array}$ \\
\hline $\begin{array}{ll}\text { sociais } & \text { de } \\
\text { técnicos } & \text { de }\end{array}$ & da. & $\begin{array}{l}\text { em } \\
\text { educação }\end{array}$ & & s sociais \\
\hline
\end{tabular}




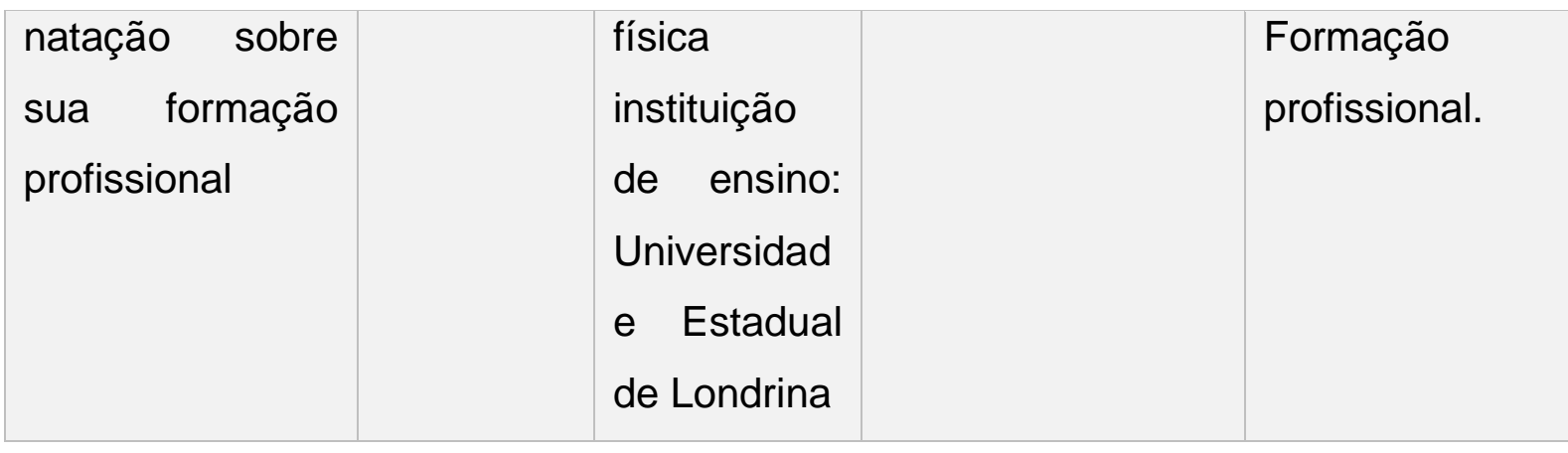

Fonte: os autores.

Como foram identificadas poucas pesquisas sobre a profissão de Educação Física na primeira busca, optou-se em realizar uma busca sem delimitação temporal, mesmo sabendo da dificuldade em localizar as palavras-chave, resumo e texto completo. A busca completa e específica mostrou-se importante para a compreensão da capilaridade e importância da produção acadêmica sobre RS da profissão de Educação Física nos cursos de pós-graduação do Brasil, mesmo que mais antiga.

No segundo momento (segundo filtro) a busca foi mais específica para a área de Educação Física, ou seja, os termos utilizados foram "representações sociais" AND "educação física" AND profissão (primeiro e segundo termo entre aspas e com o operador booleano AND entre os termos).

Também foram realizadas buscas (terceiro filtro) acrescentando o termo profiss * (com o asterisco para recuperar as palavras com as variações dos sufixos) no lugar de profissão, ampliando a possibilidade de resultados.

\section{RESULTADOS}

Com estes termos de busca e critérios e sem delimitação temporal foram identificadas seis (06) pesquisas com o segundo filtro de busca e sete (07) com o terceiro, ou seja, um total de 13 pesquisas. Destas, oito (08) pesquisas de mestrado e cinco (05) de doutorado, sendo que três (03) já haviam sido localizadas na primeira busca (Quadro 1). 
Assim, das pesquisas identificadas sete (07) são anteriores à Plataforma Sucupira, portanto não possuem palavras-chave, resumo e texto completo disponíveis. Contudo, três (03) destas pesquisas foram localizadas em outros endereços eletrônicos. Uma das pesquisas (KONRATH, 2015), já disponíveis na Plataforma Sucupira, não possui divulgação autorizada, mas possui resumo e palavras-chave, permitindo sua análise.

Deste modo, foram analisadas nove (09) pesquisas sobre RS da profissão de Educação Física, sendo três pesquisas anteriores à plataforma Sucupira (identificadas e localizadas) e seis pesquisas disponíveis na plataforma, com os critérios de inclusão apresentados. As pesquisas não disponíveis no Catálogo de Teses e Dissertações da CAPES ou em outro sítio não foram analisadas, pelo motivo óbvio de falta de dados e informações.

Abaixo os quadros 2 e 3 com as respectivas pesquisas e critérios de busca.

QUADRO 2- Pesquisas de mestrado e doutorado relacionadas à RS sobre a profissão de Educação Física até 2019 ("representações sociais" AND "educação física" AND profissão)

\begin{tabular}{|c|c|c|c|}
\hline $\begin{array}{l}\text { TÍTUL } \\
\text { O }\end{array}$ & $\begin{array}{l}\text { AU } \\
\text { TO } \\
\text { R }\end{array}$ & $\begin{array}{l}\text { DADO } \\
S\end{array}$ & $\begin{array}{l}\text { PALAVRAS-CHAVE } \\
\text { Na plataforma Sucupira ou localizadas em outra base de } \\
\text { dados ou site }\end{array}$ \\
\hline $\begin{array}{l}\text { Repres } \\
\text { entaçõ } \\
\text { es } \\
\text { sociais } \\
\text { de } \\
\text { mulher } \\
\text { es } \\
\text { técnica } \\
\text { s sobre }\end{array}$ & $\begin{array}{l}\text { Oliv } \\
\text { eira } \\
\text { Gab } \\
\text { riela } \\
\text { Ara } \\
\text { gão } \\
\text { S } \\
\text { de. }\end{array}$ & $\begin{array}{l}2002 \\
\text { Mestr } \\
\text { ado } \\
\text { em } \\
\text { EDUC } \\
\text { AÇÃO } \\
\text { FÍSIC } \\
\text { A } \\
\text { Institui }\end{array}$ & $\begin{array}{l}\text { http://www.nuteses.temp.ufu.br/tde_busca/processaPesqu } \\
\text { isa.php?pesqExecutada=2\&id=149\&listaDetalhes\%5B\%5 } \\
D=149 \& p r o c e s s a r=P r o c e s s a r \\
\text { Educação física; mulheres técnicas; alto nível. }\end{array}$ \\
\hline
\end{tabular}




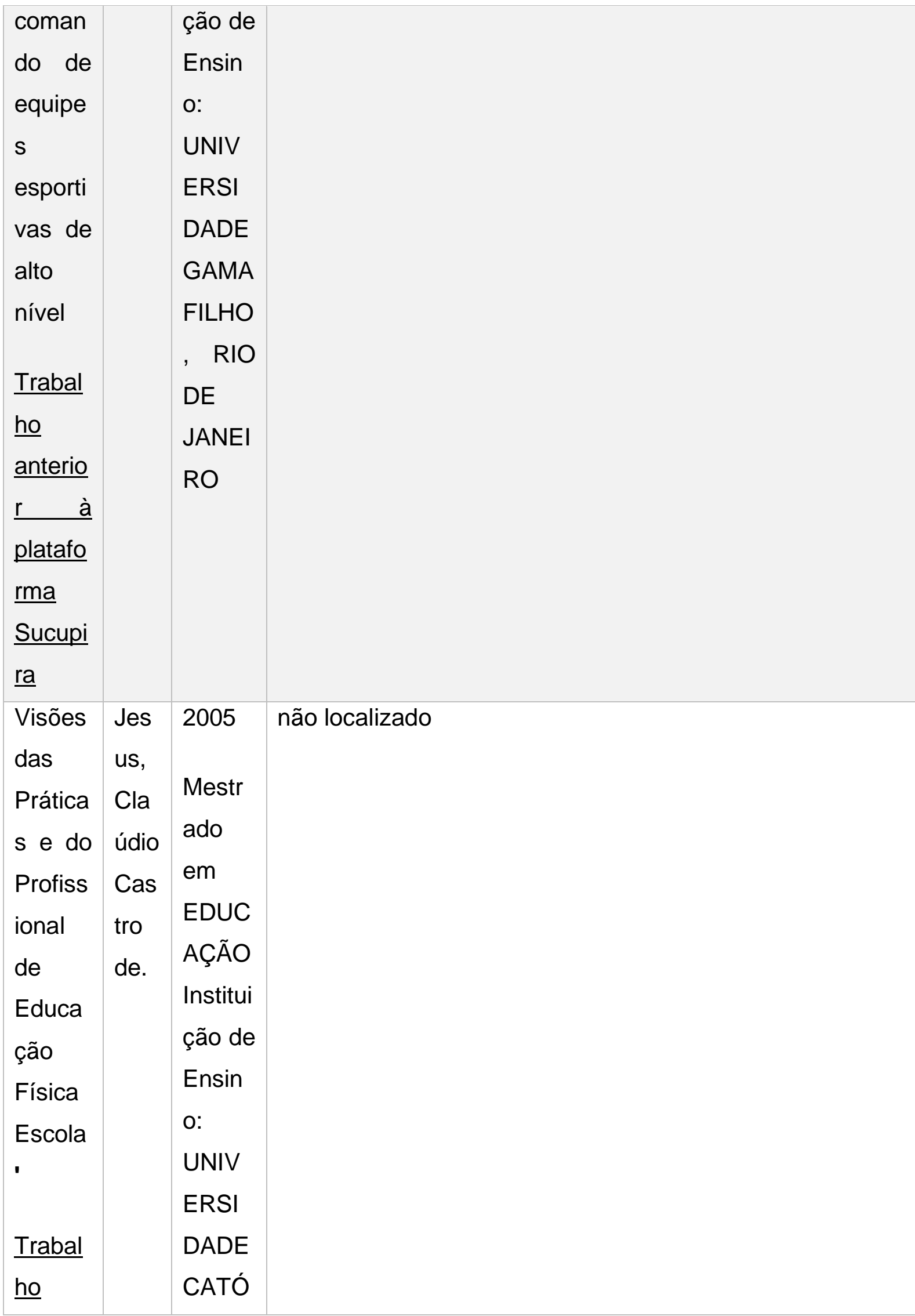




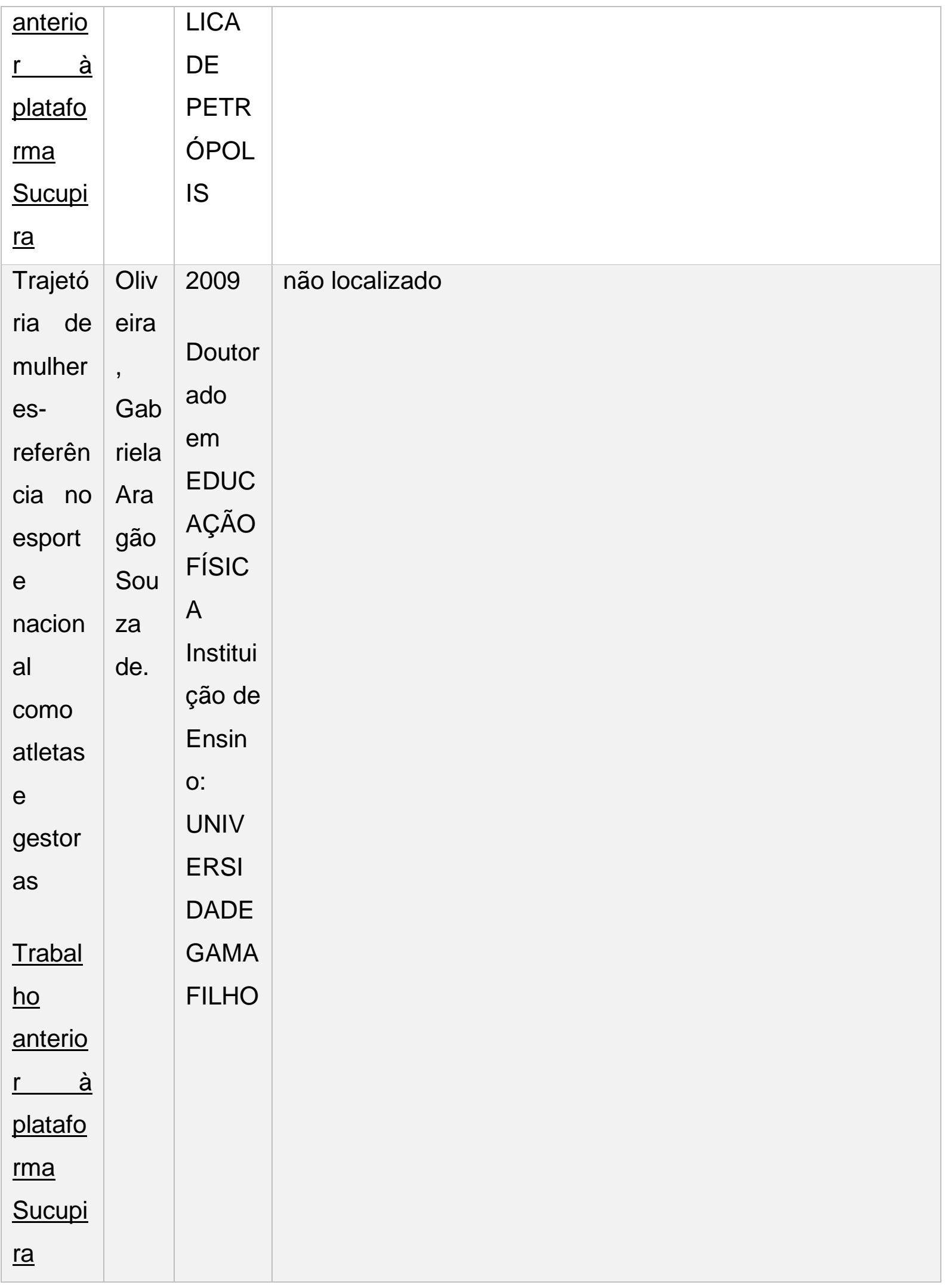




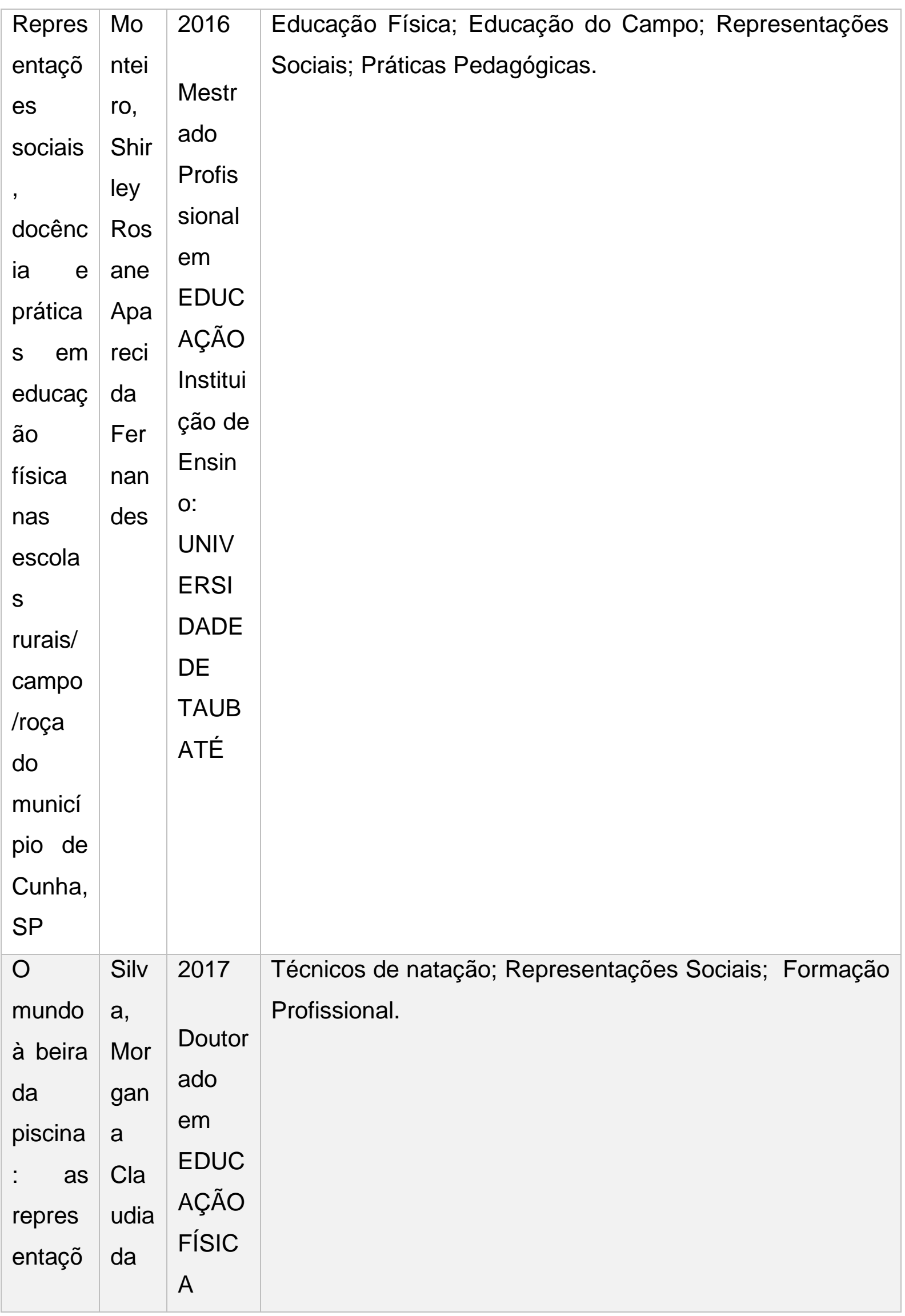




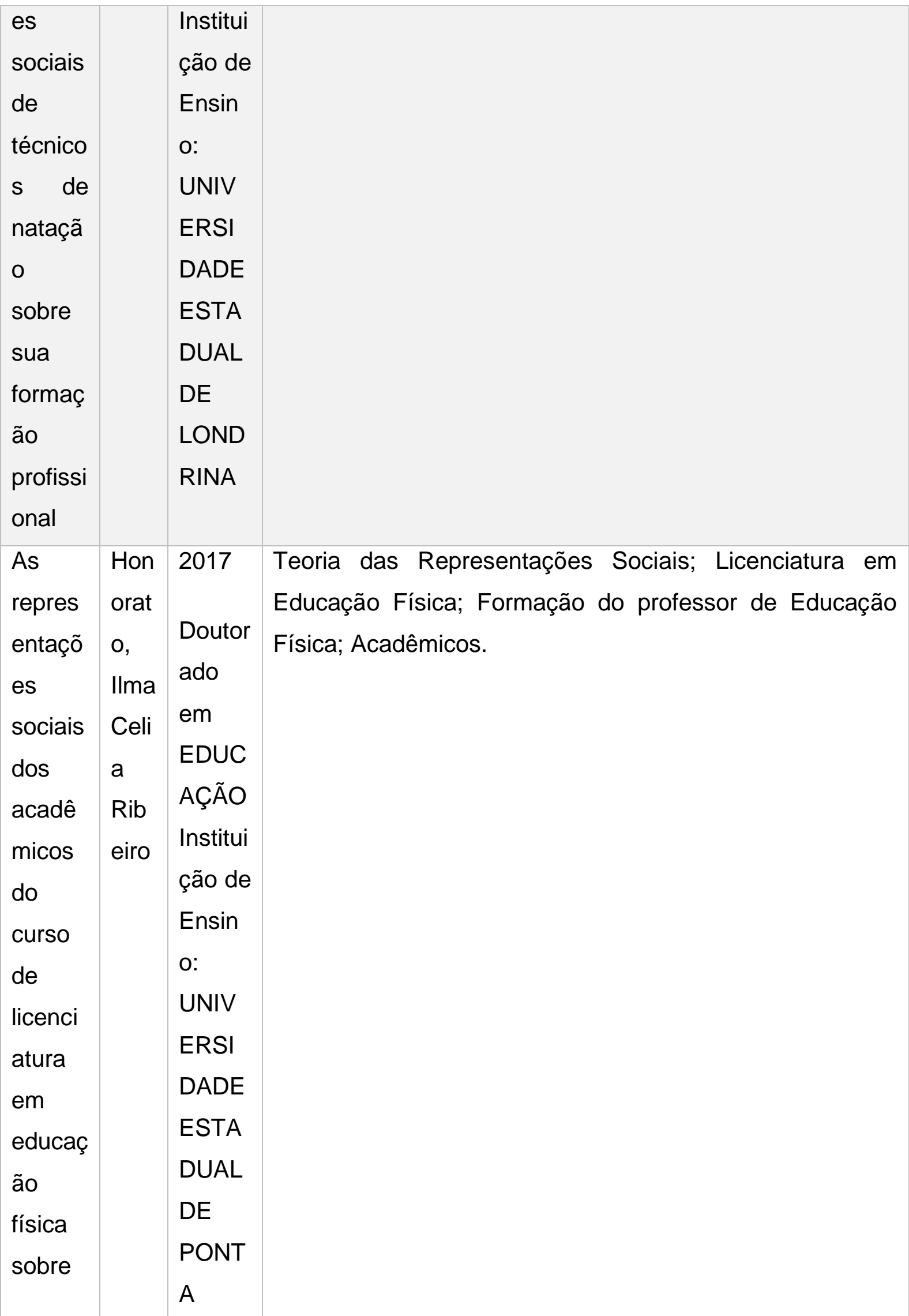




\begin{tabular}{|l|l|}
\hline $\begin{array}{l}\text { o que é } \\
\text { ser }\end{array}$ & $\begin{array}{l}\text { GROS } \\
\text { profes } \\
\text { sor }\end{array}$ \\
\hline
\end{tabular}

Fonte: os autores.

QUADRO 3- Pesquisas de mestrado e doutorado relacionadas à RS sobre a profissão de Educação Física até 2019 ("representações sociais" AND "educação física" AND profiss $^{*}$ )

\begin{tabular}{|c|c|c|c|}
\hline $\begin{array}{l}\text { TÍTUL } \\
\text { O }\end{array}$ & $\begin{array}{l}\mathrm{AU} \\
\mathrm{TO} \\
\mathrm{R}\end{array}$ & $\begin{array}{l}\text { DAD } \\
\text { OS }\end{array}$ & $\begin{array}{l}\text { PALAVRAS-CHAVE } \\
\text { (ANTES DE } 2013 \text { LOCALIZADAS EM OUTRA BASE DE } \\
\text { DADOS OU SITE) }\end{array}$ \\
\hline $\begin{array}{l}\text { O } \\
\text { discur } \\
\text { so do } \\
\text { profiss } \\
\text { ional } \\
\text { de } \\
\text { ginásti } \\
\text { ca em } \\
\text { grand } \\
\text { es } \\
\text { acade } \\
\text { mias } \\
\text { no Rio } \\
\text { de } \\
\text { Janeir } \\
\text { o }\end{array}$ & $\begin{array}{l}\text { Coe } \\
\text { Iho } \\
\text { Filh } \\
\text { o, } \\
\text { Carl } \\
\text { os } \\
\text { Alb } \\
\text { erto } \\
\text { De } \\
\text { And } \\
\text { rad } \\
\text { e. }\end{array}$ & $\begin{array}{l}1998 \\
\text { Mest } \\
\text { rado } \\
\text { em } \\
\text { educ } \\
\text { ação } \\
\text { física } \\
\text { Univ } \\
\text { ersid } \\
\text { ade } \\
\text { Gam } \\
\text { a } \\
\text { Filho }\end{array}$ & $\begin{array}{l}\text { Análise de discurso } \\
\text { Representações } \\
\text { Gênero } \\
\text { Idade } \\
\text { Imagem } \\
\text { Educação } \\
\text { http://www.nuteses.temp.ufu.br/tde_busca/processapesquis } \\
\text { a.php?pesqexecutada=2\&id=264\&listadetalhes\%5b\%5d=26 } \\
\text { 4\&processar=processar }\end{array}$ \\
\hline
\end{tabular}




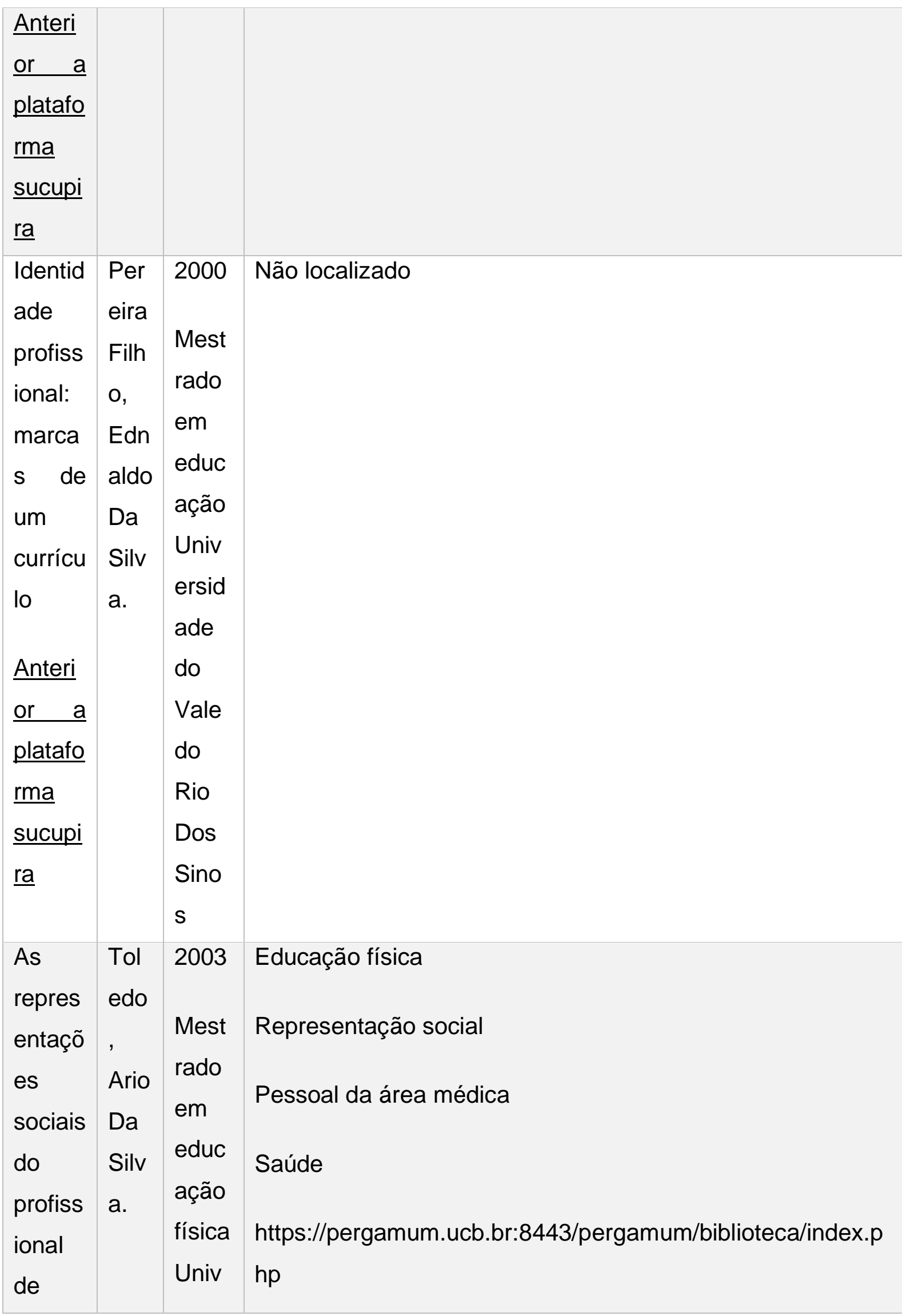




\begin{tabular}{|c|c|c|c|}
\hline $\begin{array}{l}\text { educa } \\
\text { ção } \\
\text { física } \\
\text { constr } \\
\text { uídas } \\
\text { por } \\
\text { profiss } \\
\text { ionais } \\
\text { de } \\
\text { saúde } \\
\underline{\text { Anteri }} \\
\underline{\text { or a }} \\
\text { platafo } \\
\underline{\text { rma }} \\
\underline{\text { sucupi }} \\
\underline{\text { ra }}\end{array}$ & $\begin{array}{l}\text { Gut } \\
\text { h, } \\
\text { Fab } \\
\text { iula } \\
\text { Apa } \\
\text { reci } \\
\text { da } \\
\text { Ben } \\
\text { to. }\end{array}$ & $\begin{array}{l}2008 \\
\text { Mest } \\
\text { rado } \\
\text { em } \\
\text { educ } \\
\text { ação } \\
\text { Univ } \\
\text { ersid } \\
\text { ade } \\
\text { Fede } \\
\text { ral de } \\
\text { Mato } \\
\text { Gros } \\
\text { so }\end{array}$ & $\begin{array}{l}\text { http://www.biblioteca.ufmt.br/pergamum/biblioteca/index.php } \\
\text { Texto não disponível on-line }\end{array}$ \\
\hline
\end{tabular}


da

UFMT, sobre

0

futuro

do

trabalh

0

docent

e: um

estudo

sobre

razões

para

ser

profes

sor,

ativida

des

docent

es

atuais

e

futuras

e do

que

depen

derá o

trabalh

0 do 


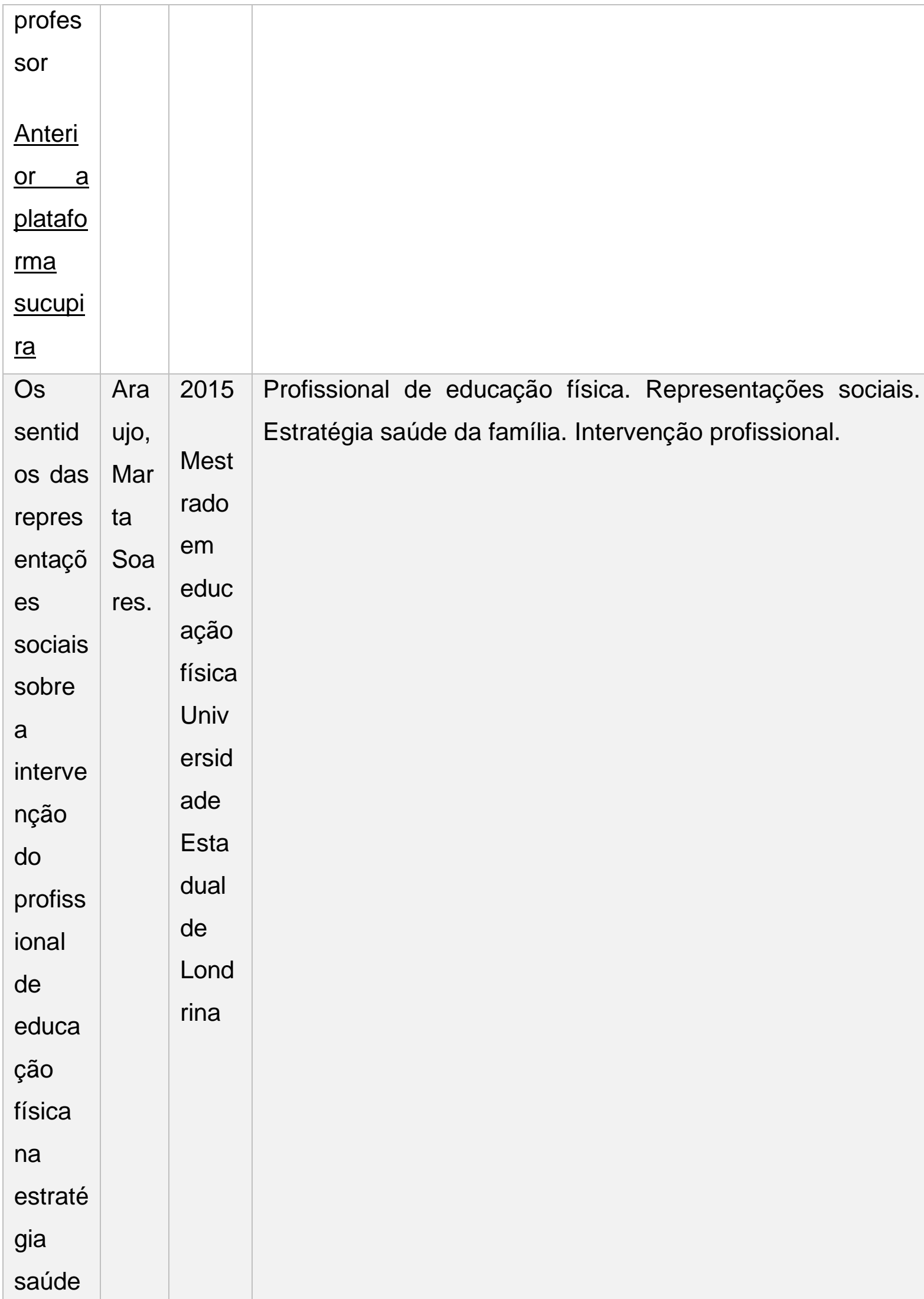




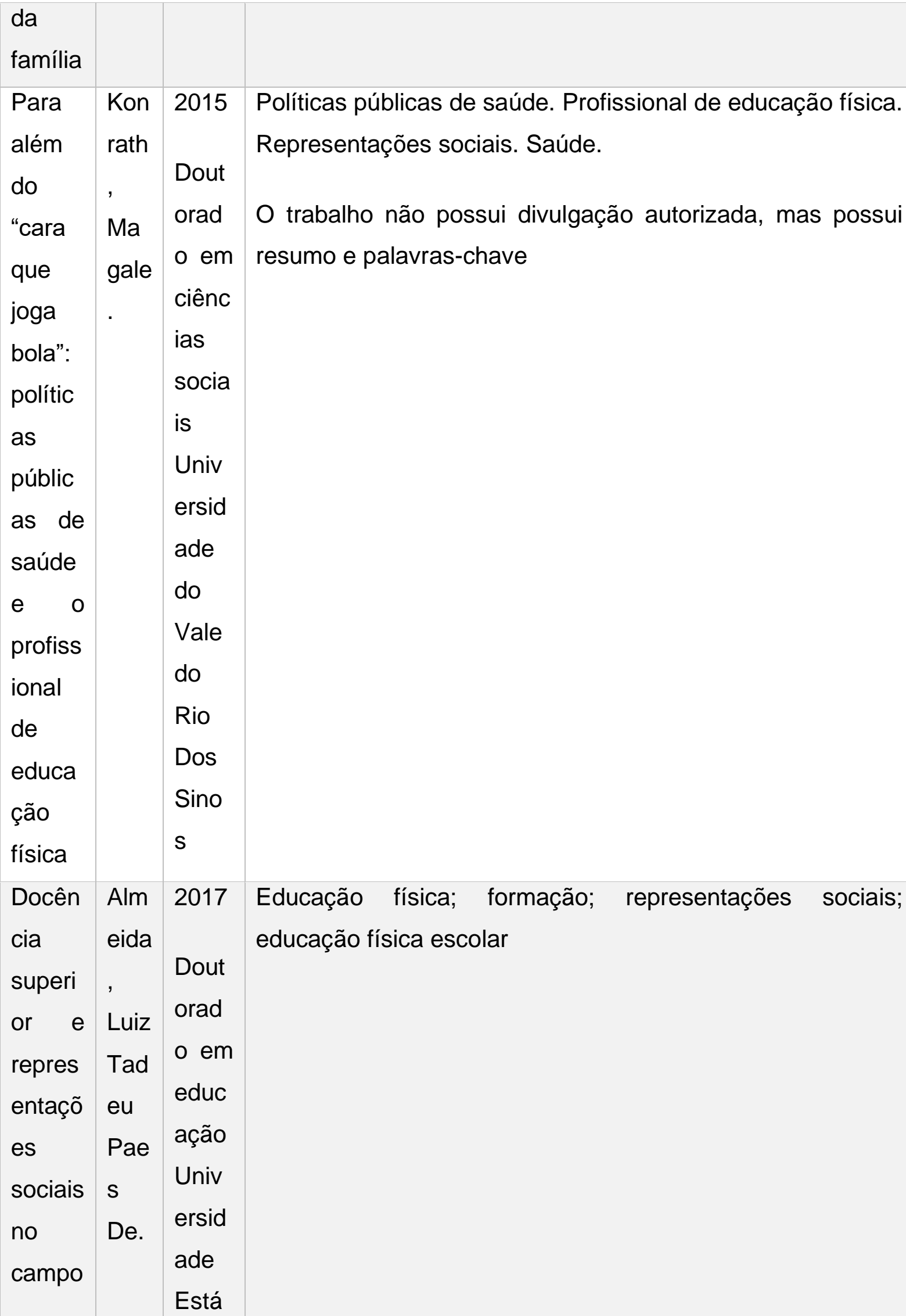




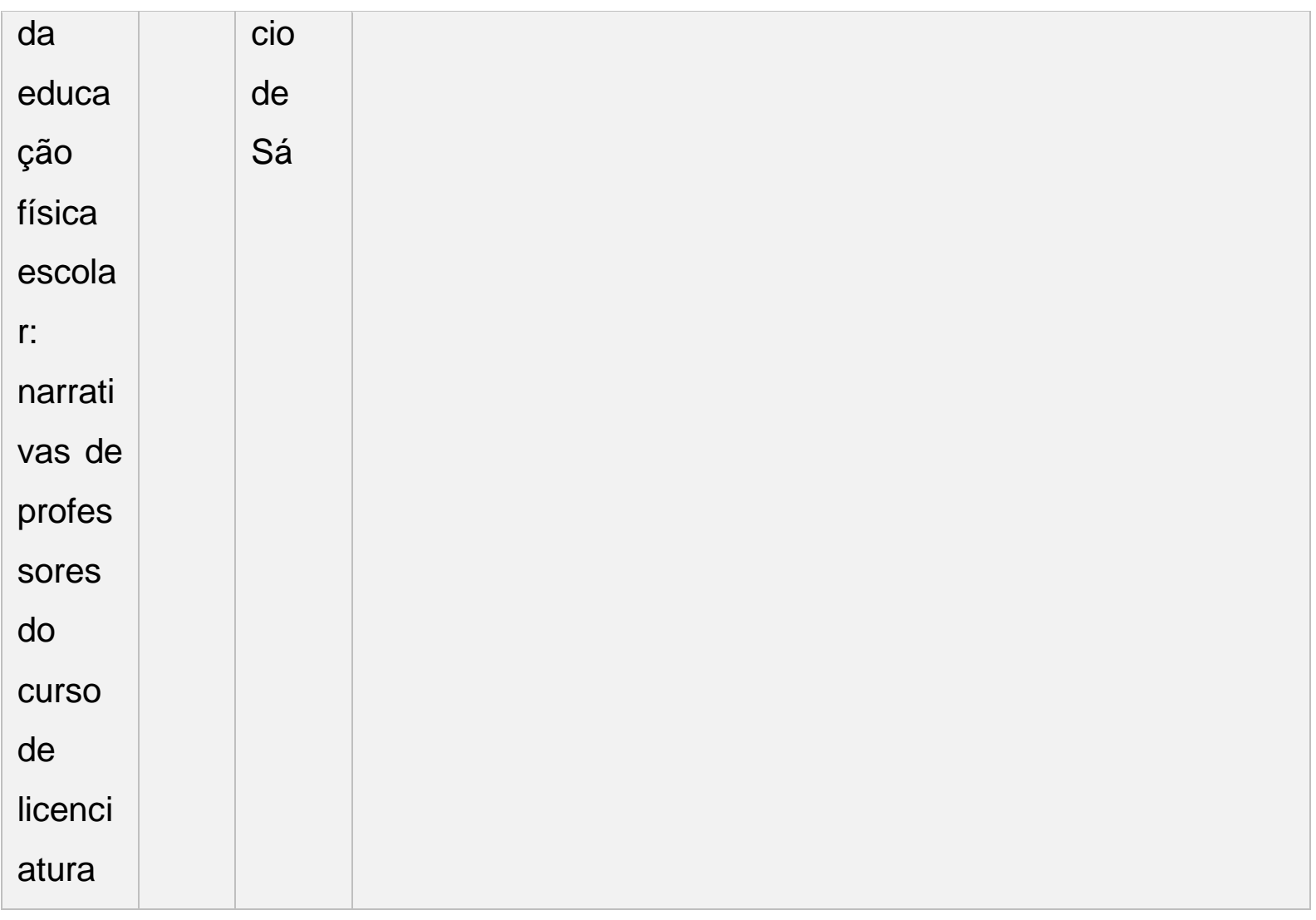

Fonte: os autores.

Após as buscas no Catálogo de Teses e Dissertações da CAPES realizou-se a busca no Portal de Periódicos da CAPES. Foram utilizados os mesmos parâmetros para a busca, ou seja, os mesmos termos, operadores e critérios de inclusão. Porém, com a delimitação temporal de 5 anos, entre 2015 e 2020.

Contudo, foi identificado somente um artigo, com os critérios elencados, que aborda a RS sobre profissão a profissão de Educação Física. Abaixo os dados do artigo (quadro 4).

QUADRO 4- Artigo relacionado a RS sobre a profissão de Educação Física no Portal de Periódicos da CAPES.

TÍTULO
DADOS
PALAVRAS-

CHAVE 


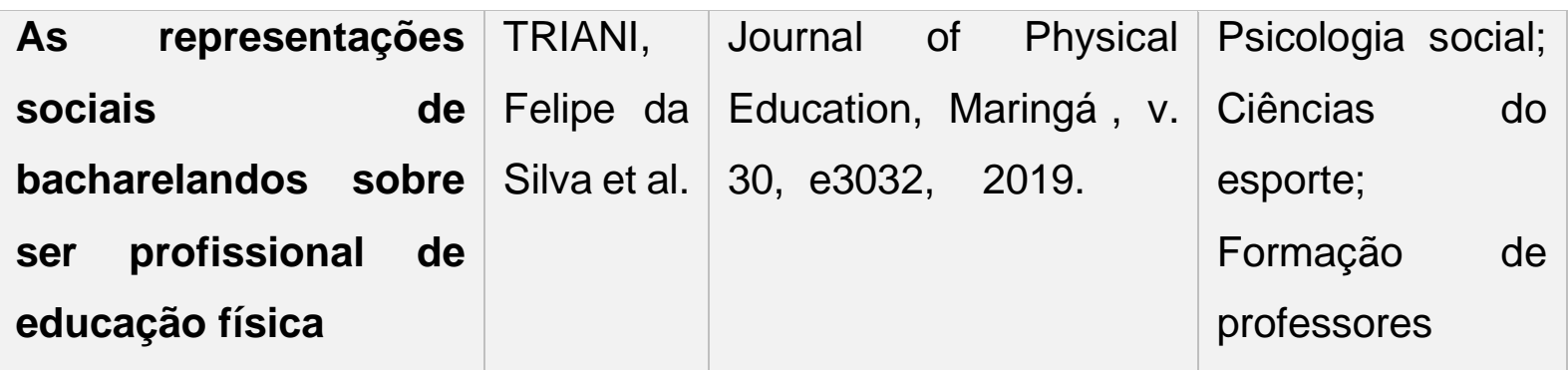

Fonte: os autores.

$\mathrm{Na}$ tentativa de identificar outros artigos, com os critérios definidos, optou-se em realizar uma busca nos sites de periódicos específicos de Educação Física. A busca foi realizada em periódicos científicos brasileiros com escopo na área de Educação Física, Esporte e Lazer, classificados entre os estratos A1 e B2 do Qualis Periódicos da CAPES na plataforma SUCUPIRA, na área de avaliação Educação Física e classificação nos anos de 2013-2016, na versão on-line.

Os periódicos são: Revista Brasileira de Medicina do Esporte, Revista Movimento, Motriz: Revista de Educação Física, Revista Brasileira de Cineantropometria e Desempenho Humano, Revista Brasileira de Educação Física e Esporte, Revista Brasileira de Ciências do Esporte, Licere, Pensar a Prática, Revista Brasileira de Biomecânica, Revista Brasileira de Ciência e Movimento e Revista Brasileira de Atividade Física e Saúde (Quadro 5).

QUADRO 5 - Periódicos brasileiros com QUALIS CAPES entre A1 e B2

\begin{tabular}{|c|c|c|c|c|c|}
\hline $\begin{array}{l}\text { Nome } \\
\text { periódico }\end{array}$ & do & Endereço eletrônico & & $\begin{array}{l}\text { ISSN } \\
- \\
\text { versã } \\
\text { o on- } \\
\text { line }\end{array}$ & $\begin{array}{l}\text { Quali } \\
\text { s }\end{array}$ \\
\hline $\begin{array}{l}\text { Revista } \\
\text { Brasileira } \\
\text { Medicina } \\
\text { Esporte }\end{array}$ & $\begin{array}{l}\text { de } \\
\text { do }\end{array}$ & $\begin{array}{l}\text { https://rbme.org/ e } \\
\text { bin/wxis.exe/iah/ }\end{array}$ & http://www.scielo.br/cgi- & $\begin{array}{l}1806 \\
- \\
9940\end{array}$ & A2 \\
\hline
\end{tabular}




\begin{tabular}{|c|c|c|c|}
\hline $\begin{array}{l}\text { Revista } \\
\text { Movimento }\end{array}$ & https://seer.ufrgs.br/Movimento/index & $\begin{array}{l}1982 \\
- \\
8918\end{array}$ & A2 \\
\hline $\begin{array}{l}\text { Motriz: Revista } \\
\text { de Educação } \\
\text { Física }\end{array}$ & $\begin{array}{l}\text { http://www.scielo.br/scielo.php?script=sci_serial\& } \\
\text { pid=1980-6574\&lng=en\&nrm=iso }\end{array}$ & $\begin{array}{l}1980 \\
- \\
6574\end{array}$ & B1 \\
\hline $\begin{array}{l}\text { Revista } \\
\text { Brasileira de } \\
\text { Cineantropome } \\
\text { tria e } \\
\text { Desempenho } \\
\text { Humano }\end{array}$ & $\begin{array}{l}\text { https://periodicos.ufsc.br/index.php/rbcdh/index e } \\
\text { http://www.scielo.br/scielo.php?script=sci_serial\& } \\
\text { pid=1980-0037\&lng=pt\&nrm=iso }\end{array}$ & $\begin{array}{l}1980 \\
- \\
0037\end{array}$ & B1 \\
\hline $\begin{array}{l}\text { Revista } \\
\text { Brasileira de } \\
\text { Educação } \\
\text { Física } \\
\text { Esporte }\end{array}$ & $\begin{array}{l}\text { https://www.revistas.usp.br/rbefe e } \\
\text { http://www.scielo.br/scielo.php?script=sci_serial\& } \\
\text { pid=1807-5509\&lng=pt\&nrm=iso }\end{array}$ & $\begin{array}{l}1981 \\
- \\
4690\end{array}$ & B1 \\
\hline $\begin{array}{l}\text { Revista } \\
\text { Brasileira de } \\
\text { Ciências do } \\
\text { Esporte }\end{array}$ & $\begin{array}{l}\text { http://revista.cbce.org.br/index.php/RBCE/index e } \\
\text { http://www.scielo.br/scielo.php?script=sci_serial\& } \\
\text { pid=0101-3289\&lng=pt\&nrm=iso }\end{array}$ & $\begin{array}{l}2179 \\
- \\
3255\end{array}$ & B1 \\
\hline Licere & https://periodicos.ufmg.br/index.php/licere/index & $\begin{array}{l}1981 \\
- \\
3171\end{array}$ & B2 \\
\hline $\begin{array}{l}\text { Pensar a } \\
\text { Prática }\end{array}$ & https://www.revistas.ufg.br/fef/index & $\begin{array}{l}1980 \\
- \\
6183\end{array}$ & B2 \\
\hline $\begin{array}{l}\text { Revista } \\
\text { Brasileira de } \\
\text { Biomecânica }\end{array}$ & $\begin{array}{l}\text { http://citrus.uspnet.usp.br/biomecan/ojs/index.ph } \\
\text { p/rbb/index }\end{array}$ & $\begin{array}{l}1518 \\
- \\
8191\end{array}$ & B2 \\
\hline
\end{tabular}




\begin{tabular}{|c|c|c|c|}
\hline $\begin{array}{l}\text { Revista } \\
\text { Brasileira de } \\
\text { Ciência e } \\
\text { Movimento }\end{array}$ & https://portalrevistas.ucb.br/index.php/RBCM & $\begin{array}{l}0103 \\
- \\
1716\end{array}$ & B2 \\
\hline $\begin{array}{l}\text { Revista } \\
\text { Brasileira de } \\
\text { Atividade } \\
\text { Física e Saúde }\end{array}$ & http://www.rbafs.org.br/RBAFS & $\begin{array}{l}2317 \\
- \\
1634\end{array}$ & B2 \\
\hline
\end{tabular}

Fonte: os autores.

Além do artigo identificado no Portal de Periódicos da CAPES, conforme o quadro 4, foram localizados mais dois artigos com os critérios elencados. Abaixo os dados do artigo (quadro 5). Logo, foram identificados três (03) artigos referentes às RS sobre a profissão de Educação Física.

QUADRO 6- Artigos relacionados a RS sobre a profissão de Educação Física em periódicos da área.

\begin{tabular}{|c|c|c|c|}
\hline TÍTULO & AUTOR & DADOS & PALAVRAS-CHAVE \\
\hline $\begin{array}{lr}0 \quad \text { discurso do } \\
\text { profissional de } \\
\text { ginástica } \\
\text { academia no Rio de } \\
\text { Janeiro }\end{array}$ & $\begin{array}{l}\text { Carlos Alberto } \\
\text { de Andrade } \\
\text { Coelho Filho }\end{array}$ & $\begin{array}{l}\text { Movimento. v. 6, } \\
\text { n. } 12(2000)\end{array}$ & $\begin{array}{l}\text { Ginástica. Lazer. } \\
\text { Gênero. } \\
\text { Representações. }\end{array}$ \\
\hline $\begin{array}{l}\text { A representação } \\
\text { social de estudantes } \\
\text { de Educação Física } \\
\text { sobre o campo } \\
\text { profissional }\end{array}$ & $\begin{array}{l}\text { Yara Osório; } \\
\text { Monique } \\
\text { Ribeiro Assis; } \\
\text { Guilherme } \\
\text { Pereira. }\end{array}$ & $\begin{array}{l}\text { Pensar a } \\
\text { Prática, Goiânia, } \\
\text { v. 16, n. 2, p. } \\
\text { 320618, } \\
\text { abr./jun. 2013. }\end{array}$ & $\begin{array}{l}\text { Educação Física e } \\
\text { Treinamento. } \\
\text { Comportamento social. } \\
\text { Ética. Atividades de } \\
\text { Lazer. }\end{array}$ \\
\hline
\end{tabular}

Fonte: os autores. 
Na sequência será apresentada a análise e discussão dos estudo identificados, com base no referencial teórico da TRS e da Educação Física.

\section{ANÁLISE DAS PESQUISAS IDENTIFICADAS NO LEVANTAMENTO DE DISSERTAÇÕES, TESES E ARTIGOS}

As análises foram realizadas com base nos resumos disponíveis da pesquisa e leitura posterior de detalhes no texto, quando disponíveis. As categorias identificadas para a análise foram:

1. Campo de atuação profissional da educação física abordado.

2. Métodos de coleta de dados/informações.

3. Principais conclusões sobre as RS da profissão de Educação Física.

A dissertação de mestrado "O discurso do profissional de ginástica em grandes academias no Rio de Janeiro" (COELHO FILHO, 1998) teve como sujeitos profissionais de ginástica de grandes academias e profissionais de ginástica proprietários de pequenas academias. A coleta de dados foi feita através de entrevista guiada e da observação participante. Os resultados concluem que há restrições com a atuação de mulheres e com profissionais mais velhos. Também, constatou-se que o professor privilegia o papel de educador, enquanto o proprietário visa mais o lucro. Portanto, uma desvalorização profissional e dificuldade em seguir uma carreira neste ramo de atuação.[6]

A pesquisa de mestrado "Representações sociais de mulheres técnicas sobre o comando de equipes esportivas de alto nível" (OLIVEIRA, 2002) utilizou como métodos as entrevistas semiestruturadas e as anotações de campo. Todas as técnicas entrevistadas foram atletas de destaque e contratadas para treinar as equipes dos clubes que atuaram. São formadas em Educação Física e possuem curso de formação para técnicos. O estudo conclui que a RS da mulher como técnica está pautada nas influências do gênero, com reserva masculina e resistência dos dirigentes para a contratação de mulheres neste campo de atuação profissional. (OLIVEIRA, 2002). 
[...] declaram que para comandar equipes de alto nível as mulheres primeiro têm que vivenciar o esporte. Ser ex-atleta é pré-requisito para que elas atuem no treinamento, do contrário, não há respeito. São outros requisitos: estudo, disciplina, organização, dedicação, liderança, criatividade, coragem, perseverança, espírito de vencedor, sorte para treinar bons atletas e estrutura emocional para superar as exigências competitivas da profissão. (OLIVEIRA, 2002, p. 67).

A pesquisa de mestrado "As representações sociais do profissional de educação física construídas por profissionais de saúde" (TOLEDO, 2003) utilizou dois instrumentos de pesquisa, um questionário e uma entrevista com a técnica de associação livre. Como conclusão o estudo identificou como RS a saúde, o condicionamento físico e as atividades físicas.

Todas essas concepções criadas a respeito do profissional de educação física se referem a aspectos positivos e provavelmente não irão orientar condutas nocivas em relação à pessoa do profissional de educação física, não interferindo negativamente numa possível integração deste na composição das equipes multidisciplinares de saúde. (TOLEDO, 2003, p. 54).

A dissertação de mestrado "Os sentidos das representações sociais sobre a intervenção do profissional de educação física na Estratégia Saúde da Família (ESF)" (ARAUJO, 2015) coletou os dados por meio de entrevistas semiestruturadas. Os resultados da pesquisa apontam a RS para o distanciamento existente entre a formação inicial e o exercício profissional e aproximação com a ESF e SUS.

O núcleo central identificado remete aos sentidos atribuídos pelos atores sociais à própria ESF. Nele as estruturas discursivas analisadas foram elaboradas a partir da apropriação dos valores norteadores da ESF, sendo esta última entendida como recurso basilar de consolidação, ampliação e qualificação do Sistema Único de Saúde (SUS) [...] Neste sentido, listam, inclusive, os aspectos que acreditam ser determinantes ao sucesso da ESF: aumentar a contratação e melhorar a formação (profissional e humana) de seus recursos humanos; investir mais em recursos materiais e estrutura física adequada. (ARAÚJJ, 2015, p. 9394).

A pesquisa de doutorado "Para além do 'cara que joga bola': políticas públicas de saúde e o profissional de educação física" tem por objetivo identificar e analisar as RS de gestores, profissionais de Educação Física e usuários sobre a inserção do 
profissional de Educação Física nas políticas públicas de saúde. (KONRATH, 2015). Como instrumento de coleta de informações utilizou entrevista semiestruturada, observação não participante, grupo focal, análise documental e diário de campo. Os resultados mostram como RS um profissional de Educação Física autocrítico, enquanto gestores e usuários enaltecem os aspectos positivos. Também o conflito entre professor versus o profissional e a comparação com outras profissões da área da saúde são apresentados com resultado das RS.

No estudo "Representações sociais, docência e práticas em educação física nas escolas rurais/campo/roça do município de Cunha, SP" (MONTEIRO, 2016) os sujeitos são professores de educação física e polivalentes de escolas rurais. Os métodos foram registro fotográfico, entrevista semiestruturada e questionário. Como conclusão são apresentadas RS favoráveis e desfavoráveis da profissão de educação física. A profissão é considerada útil, bonita e exige criatividade, porém é desvalorizada, pesada e sem reconhecimento social. Contudo, é valorizada pela comunidade rural.

Os professores, conforme os resultados da pesquisa, percebem a profissão como desvalorizada, sem reconhecimento social, pouco atraente e pesada. Essa desvalorização se materializa pelas más condições de trabalho, baixo salário, falta de materiais e espaços adequados para as aulas, falta de planejamento e de equiparação das condições rural/urbano. Em contraposição, os professores percebem a profissão como útil, complexa, desafiadora, justificando assim a necessidade de sua prática profissional e as representações positivas que fazem de si. [...] A valorização da profissão de professor no município relaciona-se ao status social (principalmente na roça), à estabilidade profissional, ao tipo de trabalho, à empregabilidade para as mulheres e às condições salariais. (MONTEIRO, 201, p. 262-263).

A tese de doutorado "O mundo à beira da piscina: as representações sociais de técnicos de natação sobre sua formação profissional" (MORGANA, 2017) tem como técnica de coleta de dados a entrevista semiestruturada e análise de discurso. As RS dos técnicos estão baseadas em suas experiências como atletas e o curso superior em Educação Física teve o papel de habilitá-los (diploma) para o exercício da profissão. 
Seus discursos remetem a um olhar inequívoco sobre sua formação no período que frequentaram a universidade, no qual para eles o papel principal da 165 universidade/faculdade era habilitá-los para a atuação de técnico, para então serem credenciados, para o exercício da profissão. A formação acadêmica aparece fortemente como informação, mas não como campo de conhecimento determinante para sua profissão. (MORGANA, 2017, p. 165).

Na pesquisa de doutorado "As representações sociais dos acadêmicos do curso de licenciatura em educação física sobre o que é ser professor" (HONORATO, 2017) a coleta de dados foi realizada por meio de um questionário aberto e a Associação Livre de Palavras. As RS apontadas para o Ser Professor e Ser Professor de Educação Física estão baseadas na responsabilidade, dedicação e comprometimento com a ação pedagógica e os conceitos centrais estão pautados no esporte e na saúde.

Verificamos que tais representações apresentam conceitos do que é "Ser professor" de forma romantizada, uma vez que assumir a profissão como um dom, supera todas as dificuldades e precariedades enfrentadas pelo professor na escola, bem como a desvalorização da profissão perante a sociedade [...] é ser dinâmico, prático e ativo, pois as características da disciplina remetem a ações corporais por meio do esporte, danças, ginásticas, lutas, jogos e brincadeiras. Essa configuração diferenciada da disciplina de Educação Física em relação as outras disciplinas na escola, faz com que o professor apresente tais disposições para possibilitar a conscientização dos alunos sobre a importância de ser saudável e realizar práticas regulares de atividade física. (HONORATO, 2017, p. 160-161).

A tese "Docência superior e representações sociais no campo da educação física escolar: narrativas de professores do curso de licenciatura" (ALMEIDA, 2017) tem como sujeitos doutores que atuam em um curso superior de licenciatura. Os procedimentos metodológicos utilizados foram pesquisa documental e entrevistas. Os resultados mostraram que as RS destes professores estão relacionadas com uma forte relação e influência do esporte, a Educação Física não era a primeira opção de curso superior, tiveram influências positivas de técnicos e professores e negativas da família, o contato com a docência na Educação Física escolar foi com as disciplinas pedagógicas na graduação, iniciaram a carreira em escolas públicas e particulares. A maioria buscou o mestrado com linhas de pesquisa voltada à escola, mas os títulos das dissertações não direcionam para isso. No doutorado esse afastamento dos 
estudos na área escolar se manteve. Também, os sujeitos mostraram forte perspectiva para atuarem no ensino superior ao concluírem o doutorado.

Utilizando a Teoria das Representações Sociais e sabendo que as práticas de higienismo, militarismo e desportivismo exerceram um longo tempo de dominação sobre a Educação Física, podemos inferir que essas práticas podem ter sido tão enraizadas nas representações sociais dos professores de Educação Física que ainda hoje, elas estão presentes nas práticas e ações docentes nas escolas de formação dos professores de Educação Física e, consequentemente, nas aulas de Educação Física desenvolvida na escola. (ALMEIDA, 2017, p. 138).

O artigo "As representações sociais de bacharelandos sobre ser profissional de educação física" (TRIANI et al., 2019) utilizou como procedimento para a coleta de dados o Teste de Associação Livre de Palavras. O estudo apresenta como núcleo central das RS dos estudantes do curso de bacharelado em Educação Física a saúde, a formação, os valores profissionais e a atividade física. Ainda, conclui que desconsidera a dimensão humanística evidenciando a dimensão biológica da área.

Logo, o conhecimento desses indícios de representações sociais sobre ser profissional de educação física denuncia a necessidade de formação humanística para o grupo investigado, a fim de que se possa transformar as representações sociais em conhecimentos que considerem as relações entre o ser humano e a sociedade, atividade fundamental do profissional de educação física na assistência à sociedade. (TRIANI et al., 2019).

O outro artigo que aborda as RS sobre a profissão de Educação Física "O discurso do profissional de ginástica em academia no Rio de Janeiro" (COELHO FILHO, 2000)[7] analisou o significado do discurso e as RS de profissionais de grandes academias do RJ, sobre o processo de trabalho. A pesquisa fez uso da entrevista guiada e da observação participante para a coleta das informações. Como principais resultados apresenta restrição contra a mulher e o profissional mais velho para a atuação neste campo. Também, não se vislumbra uma carreira nesse ramo de atuação, ficando a profissão mais próxima de uma ocupação. Ainda, as academias menores possuem relações mais pessoais, enquanto as maiores se preocupam mais com os negócios. O autor ainda afirma que o núcleo central demonstra "que o profissional de ginástica 
em qualquer academia, independentemente do seu porte, deve ter uma formação como a do professor de educação física" (COELHO FILHO, 2000, p. 21).

No artigo "A representação social de estudantes de Educação Física sobre o campo profissional" (OSÓRIO; ASSIS; PEREIRA, 2013) foi investigada as RS de alunos de graduação de Educação Física sobre o campo e a função de professor. A pesquisa utilizou como instrumento um questionário via internet. $\mathrm{Na}$ conclusão destacam-se a conduta ética e a imagem do professor animador.

É possível observar no espaço do núcleo central que a família com maior número de elementos correspondeu à ideia de dever profissional, seguida por sentimentos profissionais e expectativa profissional. O dever profissional remete aos valores éticos que são pilares de qualquer profissão, sendo necessária a criação de normas de conduta que regulamentem o exercício profissional. (OSÓRIO; ASSIS; PEREIRA, 2013, p. 540).

A seguir, apresenta-se o quadro 7, com uma síntese das análises realizadas das pesquisas de mestrado e doutorado, relacionadas às RS sobre profissão de Educação Física. Após, a discussão e interpretação dos dados.

QUADRO 7- Análise de Teses, dissertações e artigos relacionados as RS sobre profissão de Educação Física

\begin{tabular}{|c|c|c|c|c|}
\hline Pesquisas & $\begin{array}{l}\text { Campo de } \\
\text { atuação } \\
\text { profissional } \\
\text { e sujeitos }\end{array}$ & $\begin{array}{l}\text { AUTORES } \\
\text { DAS } \\
\text { ABORDAGE } \\
\text { NS } \\
\text { TEÓRICAS } \\
\text { DA TRS } \\
\text { UTILIZADOS }\end{array}$ & $\begin{array}{l}\text { Principais } \\
\text { Métodos de } \\
\text { coleta de } \\
\text { dados/informaçõ } \\
\text { es }\end{array}$ & $\begin{array}{l}\text { Principais } \\
\text { conclusões }\end{array}$ \\
\hline $\begin{array}{l}\text { 1- (COELHO } \\
\text { FILHO, } \\
\text { 1998) }\end{array}$ & $\begin{array}{l}\text { - Ginástica } \\
\text { em } \\
\text { academias }\end{array}$ & $\begin{array}{l}\text { ABRIC } \\
\text { JODELET } \\
\text { MOSCOVICI }\end{array}$ & $\begin{array}{l}\text { guiada } \\
\text { entrevista } \\
\text { participante }\end{array}$ & $\begin{array}{l}\text { - restrições à } \\
\text { atuação de } \\
\text { mulheres e mais } \\
\text { velhos }\end{array}$ \\
\hline
\end{tabular}


CONHECIMENTO https://www.nucleodoconhecimento.com.br

\begin{tabular}{|c|c|c|c|c|}
\hline & $\begin{array}{l}\text { Professores } \\
\text { Proprietários }\end{array}$ & & & $\begin{array}{l}\text { professor } \\
\text { privilegia o papel } \\
\text { de educador } \\
\text { · proprietário visa } \\
\text { lucro } \\
\text { · desvalorização } \\
\text { profissional }\end{array}$ \\
\hline $\begin{array}{l}\text { 2- } \\
\text { (OLIVEIRA, } \\
\text { 2002) }\end{array}$ & $\begin{array}{l}\text { Equipes } \\
\text { esportivas } \\
\text { de alto nível } \\
\text { - Mulheres } \\
\text { técnicas }\end{array}$ & $\begin{array}{l}\text { JODELET } \\
\text { MOSCOVICI }\end{array}$ & $\begin{array}{l}\text { entrevistas } \\
\text { semiestruturada } \\
\text { s } \\
\text { - anotações de } \\
\text { campo }\end{array}$ & $\begin{array}{l}\text { masculina } \\
\text { - reservistência para } \\
\text { a contratação de } \\
\text { mulheres }\end{array}$ \\
\hline $\begin{array}{l}\text { 3- } \\
\text { (TOLEDO, } \\
\text { 2003) }\end{array}$ & $\begin{array}{l}\text { Hospitais } \\
\text { Profissionais } \\
\text { de saúde }\end{array}$ & $\begin{array}{l}\text { ABRIC } \\
\text { JODELET }\end{array}$ & $\begin{array}{l}\text { - questionário } \\
\text { - entrevista com } \\
\text { técnica de } \\
\text { associação livre }\end{array}$ & $\begin{array}{l}\text { - saúde } \\
\text { condicionamento } \\
\text { físico } \\
\text { · atividades } \\
\text { físicas }\end{array}$ \\
\hline $\begin{array}{l}\text { 4- } \\
\text { (ARAUJO, } \\
\text { 2015) }\end{array}$ & $\begin{array}{l}\text { Sistema de } \\
\text { saúde } \\
\text { Profissionais } \\
\text { de EF }\end{array}$ & $\begin{array}{l}\text { ABRIC } \\
\text { JODELET } \\
\text { DOISE } \\
\text { MOSCOVICI }\end{array}$ & $\begin{array}{l}\text { entrevistas } \\
\text { semiestruturada } \\
\text { s }\end{array}$ & $\begin{array}{l}\text { - distanciamento } \\
\text { existente entre a } \\
\text { formação inicial e } \\
\text { o exercício } \\
\text { profissional }\end{array}$ \\
\hline $\begin{array}{l}\text { 5- } \\
\text { (KONRATH, } \\
\text { 2015) }\end{array}$ & $\begin{array}{l}\text { Políticas } \\
\text { públicas de } \\
\text { saúde }\end{array}$ & $\begin{array}{l}\text { texto não } \\
\text { disponível }\end{array}$ & $\begin{array}{l}\text { entrevista } \\
\text { semiestruturada }\end{array}$ & $\begin{array}{l}\text { - profissional de } \\
\text { Educação Física } \\
\text { autocrítico }\end{array}$ \\
\hline
\end{tabular}


CONHECIMENTO https://www.nucleodoconhecimento.com.br

\begin{tabular}{|c|c|c|c|c|}
\hline & $\begin{array}{l}\text { Gestores } \\
\text { Profissionais } \\
\text { de Educação } \\
\text { Física } \\
\text { - Usuários }\end{array}$ & & $\begin{array}{l}\text { observação } \\
\text { não participante } \\
\text { - grupo focal } \\
\text { análise } \\
\text { documental } \\
\text { - diário de campo }\end{array}$ & $\begin{array}{l}\text { - gestores } \\
\text { usuários } \\
\text { enaltecem os } \\
\text { aspectos } \\
\text { positivos } \\
\text { - conflito entre } \\
\text { professor versus } \\
\text { o profissional } \\
\text { comparação } \\
\text { com outras } \\
\text { profissões da } \\
\text { área da saúde }\end{array}$ \\
\hline $\begin{array}{l}\text { 6- } \\
\text { (MONTEIRO } \\
\text {, 2016) }\end{array}$ & $\begin{array}{l}\text { Escolas } \\
\text { rurais } \\
\text { Professores } \\
\text { de educação } \\
\text { física } \\
\cdot \\
\text { Professores } \\
\text { polivalentes }\end{array}$ & $\begin{array}{l}\text { JODELET } \\
\text { MOSCOVICI }\end{array}$ & $\begin{array}{l}\text { entrevista } \\
\text { semiestruturada } \\
\text { fotográfico } \\
\text { - questionário }\end{array}$ & $\begin{array}{l}\text { A profissão é } \\
\text { considerada útil, } \\
\text { bonita e exige } \\
\text { criatividade } \\
\text { profissão } \\
\text { desvalorizada, } \\
\text { pesada e sem } \\
\text { reconhecimento } \\
\text { social. } \\
\text { - valorizada pela } \\
\text { comunidade rural }\end{array}$ \\
\hline $\begin{array}{l}\text { 7- } \\
\text { (MORGANA } \\
\text {, 2017) }\end{array}$ & $\begin{array}{l}\text { · Natação } \\
\text { de nécnicos } \\
\text { de natação }\end{array}$ & $\begin{array}{l}\text { ABRIC } \\
\text { DOISE } \\
\text { JODELET } \\
\text { MOSCOVICI }\end{array}$ & $\begin{array}{l}\cdot \text { entrevista } \\
\text { semiestruturada } \\
\text { - análise de } \\
\text { discurso }\end{array}$ & $\begin{array}{l}\text { experiências } \\
\text { como atletas } \\
\text { formação } \\
\text { acadêmica como } \\
\text { informação, mas }\end{array}$ \\
\hline
\end{tabular}




\begin{tabular}{|c|c|c|c|c|}
\hline & & & & $\begin{array}{l}\text { não determinante } \\
\text { para a profissão }\end{array}$ \\
\hline $\begin{array}{l}\text { 8- } \\
\text { (HONORAT } \\
\text { 0, 2017) }\end{array}$ & $\begin{array}{l}\text { - Docência } \\
\text { - } \\
\text { Acadêmicos } \\
\text { de } \\
\text { licenciatura } \\
\text { em EF }\end{array}$ & $\begin{array}{l}\text { ABRIC } \\
\text { DOISE } \\
\text { JODELET } \\
\text { MOSCOVICI }\end{array}$ & $\begin{array}{l}\text { questionário } \\
\text { aberto } \\
\text { Associação } \\
\text { Livre de } \\
\text { Palavras }\end{array}$ & $\begin{array}{l}\text { responsabilida } \\
\text { de, dedicação e } \\
\text { comprometiment } \\
\text { o com a ação } \\
\text { pedagógica } \\
\text { esporte e } \\
\text { saúde }\end{array}$ \\
\hline $\begin{array}{l}\text { 9- } \\
\text { (ALMEIDA, } \\
\text { 2017) }\end{array}$ & $\begin{array}{l}\text { Docência } \\
\text { superior } \\
\text { Professores } \\
\text { doutores do } \\
\text { curso de } \\
\text { licenciatura }\end{array}$ & $\begin{array}{l}\text { ABRIC } \\
\text { DOISE } \\
\text { JODELET } \\
\text { MOSCOVICI }\end{array}$ & $\begin{array}{l}\text { pesquisa } \\
\text { documental } \\
\text { - entrevistas }\end{array}$ & $\begin{array}{l}\text { - forte relação e } \\
\text { influência do } \\
\text { esporte } \\
\text { Educação } \\
\text { Física não era a } \\
\text { primeira opção } \\
\text { de curso superior } \\
\text { influências } \\
\text { positivas de } \\
\text { técnicos } \\
\text { professores } \\
\text { influências } \\
\text { negativas da } \\
\text { família }\end{array}$ \\
\hline $\begin{array}{l}\text { 10- (TRIANI } \\
\text { et al., 2019) }\end{array}$ & $\begin{array}{l}\text { Área de EF } \\
\text { de forma } \\
\text { ampla (com } \\
\text { exceção do }\end{array}$ & $\begin{array}{l}\text { ABRIC } \\
\text { JODELET } \\
\text { MOSCOVICI }\end{array}$ & $\begin{array}{l}\text { Teste de } \\
\text { Associação Livre } \\
\text { de Palavras }\end{array}$ & $\begin{array}{l}\text { saúde, } \\
\text { formação, } \\
\text { valores } \\
\text { profissionais e } \\
\text { atividade física }\end{array}$ \\
\hline
\end{tabular}




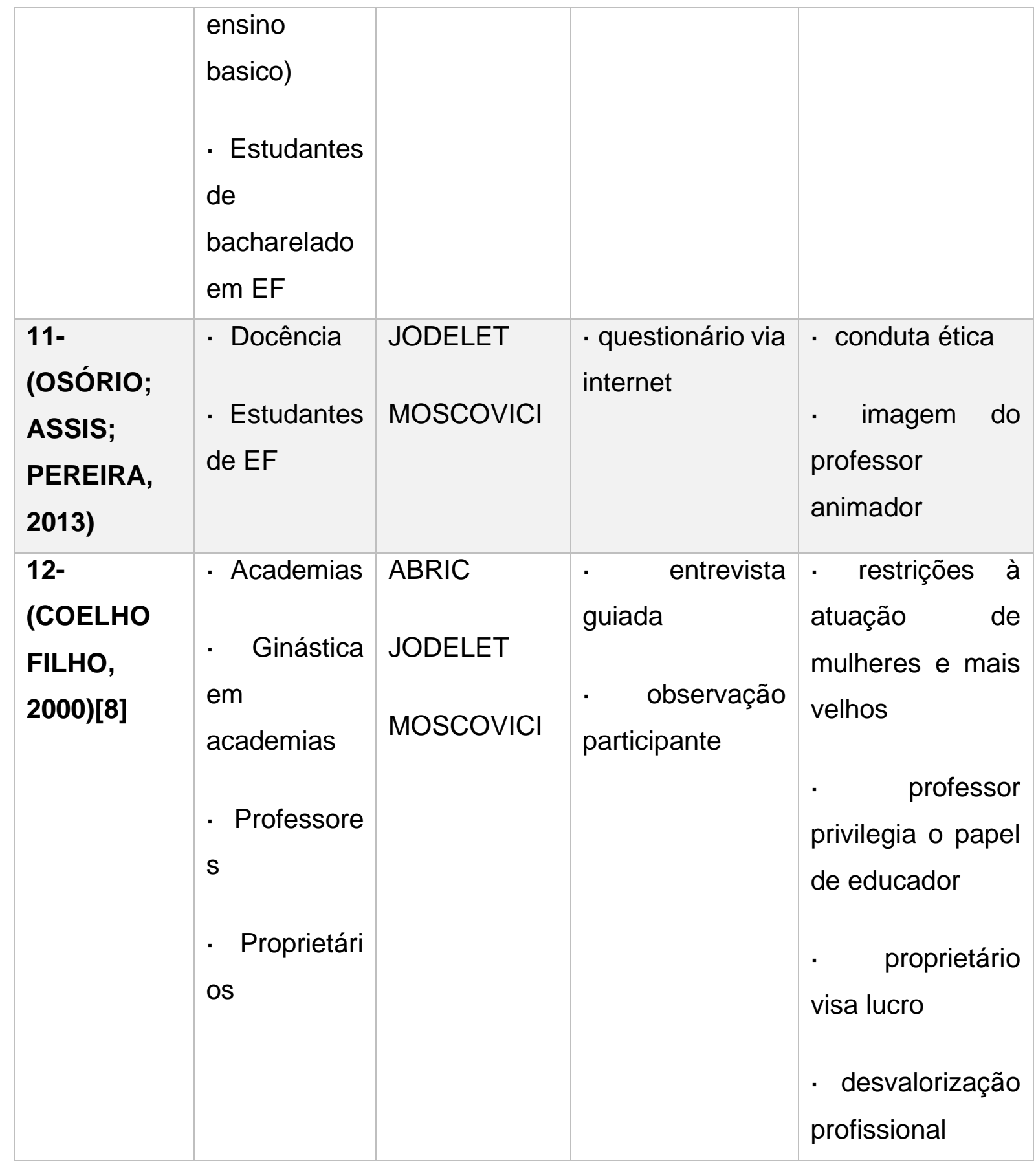

Fonte: os autores.

Com base na pesquisa sobre o estado de conhecimento foi possível identificar como características da produção acadêmica os seguintes pontos:

- Baixa frequência de estudos relacionados às RS sobre a profissão de EF.

- Diversidade de campos de atuação e sujeitos diversos. 
- Predomínio de entrevistas e questionários para a coleta de informações.

A seguir a discussão e interpretação de cada ponto identificado.

\section{DISCUSSÃO E INTERPRETAÇÃO}

\subsection{FREQUÊNCIA DE ESTUDOS SOBRE RS E PROFISSÃO DE EF}

O primeiro ponto a ser destacado é o número pequeno de pesquisas relacionadas às RS sobre a profissão de Educação Física, especialmente no século passado. Mesmo com um número maior de pesquisas nas duas primeiras décadas do século XXI, o número ainda pode ser considerado reduzido.

É importante frisar que existem mais trabalhos (artigos, dissertações e teses) sobre a profissão de Educação Física e seus diversos campos de atuação, como o esporte, a atividade física, educação física escolar, entre outros. Contudo, o intuito do presente levantamento é identificar a produção acadêmica da profissão de Educação Física à luz das Representações Sociais.

Por outro lado, alguns fatos podem explicar ou possibilitar hipóteses para este número reduzido de pesquisas.

O primeiro fato relaciona-se com a característica da formação profissional na área até a década de oitenta, aproximadamente, com as diretrizes curriculares pautadas nas Resoluções CFE 69/69 (BRASIL, 1969). Até então a formação profissional na área era do licenciado em Educação Física e do técnico desportivo. Apesar de já haver uma discussão sobre a atuação do professor de educação física em outros campos além do ensino formal, este debate e preocupação tomou fôlego com a proposta do bacharelado em educação física com a Resolução CFE 03/87, que começa a vigorar no início dos anos noventa e com os primeiros profissionais saindo para o mercado de trabalho em meados desta década. A sustentação deste modelo da formação profissional com duas habilitações ficou fortalecido com a Resolução CNE/CES no 07/2004 e com a atual Resolução CNE/CES no 06/2018. O bacharelado tem por característica habilitar o profissional para atuar no contexto extraescolar como 
atividade física, esporte e lazer, com exceção do componente curricular educação física, no ensino básico, este exclusividade dos licenciados.

Assim, um interesse acadêmico em entender esta nova dinâmica profissional e disputa no mercado teria surgido neste momento histórico de mudança curricular.

Outro fato que pode ter fortalecido este interesse e influenciando e sofrendo influências foi o movimento da proposta de regulamentação da profissão (Lei 9696/98). Além das tentativas anteriores, o final da década de oitenta e a década de noventa marcaram o debate e embate sobre a regulamentação da educação física. A busca pela demarcação do mercado de trabalho e a disputa com indivíduos não habilitados e outros profissionais que atuavam em áreas de exercício profissional pertencentes à educação física marcaram estes embates e debates. Também, um debate mais recente sobre a atuação do profissional de educação física no sistema de saúde (SUS). Estes são fatos que podem explicar um número maior de pesquisas sobre o tema profissão nas primeiras décadas deste século.

Porém, ainda é um número reduzido, principalmente quando se busca pesquisas sobre a profissão de educação física atreladas ou tendo como base teórica a Teoria das Representações Sociais (TRS). Além da teoria ser relativamente nova, tendo sua origem na década de sessenta com a obra seminal de Moscovici (1961). No Brasil, sua divulgação e disseminação aconteceu na década de oitenta, no Nordeste e Centro-Oeste do País, por meio de intercâmbio de brasileiros que na década de setenta realizaram estudos com Serge Moscovici e Denise Jodelet, na École de Hautes Études em Sciences Sociales. (ALMEIDA, 2009).

No caso específico da educação física, pode-se afirmar, que a TRS ainda não é uma teoria difundida, sendo pouco frequente na área. Em estudo sobre o estado de conhecimento, realizado por Sousa; Paula; Oliveira Junior e Antunes (2018), sobre apropriação da teoria as representações sociais pelo campo acadêmico/científico da educação física no Brasil, verificou-se a baixa frequência de estudos com a TRS. No estudo foram identificados somente 11 artigos com base na TRS, entre os anos de 2004 a 2016. Até 2009 o estudo mostrou a regularidade de um artigo por ano, porém 
com oscilação nos anos seguintes, com ausência de publicação nos anos de 2015 e 2016. Assim, o artigo conclui que

Por fim, o uso da TRS é pouco frequente no campo. Torna-se necessário aprofundar nas discussões tanto do referencial teórico, como na aplicação da teoria em estudos, principalmente no sentido de explorar as abordagens do núcleo central de Abric e a societal de Doise, visando novas interações para os estudos que perpassam o campo acadêmico/científico da Educação Física brasileira. (SOUSA et al., 2018)

Dessa forma, em uma análise mais aprofundada é possível afirmar que existe pouco interesse por este assunto no meio acadêmico, demonstrando a necessidade de mais pesquisas nesta área.

\subsection{CAMPOS DE ATUAÇÃO E SUJEITOS DE PESQUISA}

Os campos de atuação e sujeitos investigados podem ser organizados nas áreas do condicionamento físico, treinamento esportivo, docência, políticas públicas e sistema de saúde. Existe um número maior de pesquisas no campo da docência, tanto para o ensino básico quanto para o superior. Contudo, a análise das pesquisas permite verificar que os campos de atuação e sujeitos investigados são muito diversos, não existindo predomínio ou tendência para algum ramo específico da profissão de educação física.

Estes dados estão atrelados a ampliação do foco predominante de atuação como professor no ensino básico, aproximadamente até a década de oitenta, para uma ampliação dos campos de atuação do profissional de educação física. Essa ampliação levou a pressões para a regulamentação da profissão e transformações nos currículos de preparação profissional, conforme argumentado acima.

Além da demanda natural do mercado de trabalho por orientação profissional na área da atividade física, esporte e lazer, a regulamentação da profissão com a sua legislação pertinente, exigem a presença de profissionais de educação física nestas áreas. Isso pode ser percebido no artigo 3ํ. da Lei 9696/98 
Art. 3o Compete ao Profissional de Educação Física coordenar, planejar, programar, supervisionar, dinamizar, dirigir, organizar, avaliar e executar trabalhos, programas, planos e projetos, bem como prestar serviços de auditoria, consultoria e assessoria, realizar treinamentos especializados, participar de equipes multidisciplinares e interdisciplinares e elaborar informes técnicos, científicos e pedagógicos, todos nas áreas de atividades físicas e do desporto. (BRASIL, 1998, Art. 3ํ.).

Esse aumento dos campos de atuação do profissional de educação física também pode ser notado pela Classificação Brasileira de Ocupações do Ministério do Trabalho, na descrição sumária.

Coordenam, desenvolvem e orientam, com crianças, jovens e adultos, atividades físicas e práticas corporais. Ensinam técnicas desportivas; realizam treinamentos especializados com atletas de diferentes esportes; instruem-Ihes acerca dos princípios e regras inerentes a cada um deles; avaliam e supervisionam o preparo físico dos atletas; acompanham e supervisionam as práticas desportivas. Estruturam e realizam ações de promoção da saúde mediante práticas corporais, atividades físicas e de lazer na prevenção primária, secundária e terciária no SUS e no setor privado. (CBO, 2020).

Portanto, a diversidade de campos de atuação pesquisados reflete esta realidade ocupacional da área de educação física. (PRONI, 2010) ao analisar o mercado de trabalho em educação física aponta para a separação entre licenciatura e bacharelado como uma das causas para a construção da identidade profissional. Argumenta que esta divisão foi um "agente catalisador da segmentação de um mercado de trabalho que se expandiu e incorporou novas classes de atividade econômica" (PRONI, 2010, p. 795). Também, nesta mesma linha, fala da imagem da profissão além dos seus aspectos acadêmicos e legais.

Atualmente, quando se ouve a expressão "profissão Educação Física" pode-se pensar no seu sentido mais abrangente, que inclui todos os possíveis campos de atuação; ou pode-se focalizar a atenção no sentido mais restrito, que exclui os que atuam como professor escolar ou universitário. Os dois entendimentos são legítimos. De uma perspectiva histórica, trata-se de um processo dinâmico, no qual a relação entre legitimidade e legalidade pode se alterar com o passar do tempo. (PRONI, 2010, p. 796) 
Esta imagem apontada por Proni (2010) é esclarecedora e auxilia na compreensão das Representações Sociais sobre a profissão de Educação Física. Nota-se que a fragmentação e diversificação dos campos de atuação refletem e guiam o processo de preparação profissional nas Instituições de Ensino Superior com constantes alterações nas diretrizes curriculares. Consequentemente, a sociedade e a mídia, de uma forma geral, e a internet, de maneira mais específica, traduzem essas informações sobre a profissão. Como explica Moscovici (2010), este "mundo do discurso" que não nos pertence, ou melhor, que pertence aos especialistas, deve ser traduzido para estar no nosso campo de ação e penetrar no "mundo da conversação". Então, esse discurso presente no "universo reificado" do debate acadêmico da profissão é transmitido para o "universo consensual" por meio das "trocas verbais" e destes "documentos" produzidos por essas conversações.

Cada um, como 'homem comum' - fora de sua profissão -, se comporta da mesma maneira diante desses 'documentos' que são os artigos de jornal, um acidente na rua, uma discussão no café ou no clube, um livro lido, uma reportagem televisiva etc. (MOSCOVICl, 2012, p. 51).

Diante disso, pode-se dizer que estas trocas verbais e documentos também, são fortemente construídos hoje, pela divulgação de informações e notícias na internet. Como afirma Sá (1998), de acordo com Jodelet, as RS são veiculadas na vida cotidiana com bases em alguns suportes como os discursos, comportamentos, práticas, documentos, registros e meios de comunicação de massa, que atualmente, devemos incluir a internet.

[...] os discursos das pessoas e grupos que mantêm tais representações, mas também os seus comportamentos e as práticas sociais nas quais estes se manifestam. São ainda os documentos e registros em que os discursos, práticas e comportamentos ficam institucionalmente fixados e codificados. Finalmente, as interpretações que eles recebem nos meios de comunicação de massa, que dessa forma retroalimentam as representações, ou ainda - para ser mais fiel ao pensamento de Jodelet - para a sua manutenção enquanto se transformam e para a sua transformação enquanto se mantêm. (SÁ, 1998, p. 73).

Assim, é importante lembrar que "a representação social é a 'preparação para a ação', não só porque guia os comportamentos, mas sobretudo porque remodela e reconstitui 
os elementos do ambiente no qual o comportamento deve acontecer. (MOSCOVICl, 2012, p. 46)

Verificar como esses diversos campos de atuação do profissional de educação física estão representados nas notícias divulgadas na internet mostra-se como um aspecto importante para compreender as RS desta profissão.

\subsection{PREDOMÍNIO DE ENTREVISTAS E QUESTIONÁRIOS}

Outro ponto a se destacar da análise das pesquisas é o predomínio de entrevistas e questionários como instrumentos de coleta de dados/informações. Também, apresentou a associação ou evocação livre como um método valorizado. Apesar de o próprio Moscovici alertar para a não exclusividade de um método na TRS, uma tendência para métodos mais qualitativos ou métodos mistos são percebidos em pesquisas com base na teoria, uma característica da própria vertente européia das RS em oposição à corrente norte-americana com características mais experimentais. Sobre os métodos de pesquisa em RS, Moscovici (2013) se posiciona lembrando das críticas feitas sobre a ausência de modelos experimentais e quantitativos e afirma:

[...] sou fundamentalmente contra a tendência de fetichizar um método específico [...] minha posição pessoal é de que a TEORIA DAS REPRESENTAÇÕES SOCIAIS, mesmo que isso possa suscitar resistências ou discordâncias entre nós, permanecerá criativa por tão longo tempo, o quanto ela souber aproveitar as oportunidades de cada método disponível possa oferecer [...] Em suma, eu sou um metodólogo politeísta e não monoteísta. (MOSCOVICl, 2013, p. 13-14).

É interessante notar que nos questionários, entrevistas e evocações predominam como fontes de informações as construções discursivas dos sujeitos, sendo estas expressões e opiniões a matéria-prima básica para a compreensão das RS. Mesmo as pesquisas com base na abordagem estrutural das RS (Jean-Claude Abric/Grupo do Midi), de orientação experimental, utilizam a associação ou evocação livre[9]. Nesse sentido, Abric (apud SÁ 1998, p. 67) lembra que "[...] apesar de sua orientação experimental, esse Grupo recomenda que a pesquisa das representações sociais comece sempre por entrevistas em profundidade". 
Fica evidente que o perfil das pesquisas que abordam as RS da profissão de EF não está pautado em um campo de atuação específico e utiliza predominantemente questionários e entrevistas, com alguma especificidade da abordagem teórica adotada, como a técnica de associação ou evocação livre. Posto isso, entende-se que é preciso uma atenção maior com este tema de pesquisa, principalmente, com base na TRS, visto ser uma teoria que permite a aproximação entre o mundo individual e o mundo social, aproximação esta tão cara à prática profissional da educação física.

Posto isso, foi possível identificar os seguintes aspectos mais evidentes nos estudos: críticas à formação acadêmica, desvalorização profissional (autodesvalorização), valorização por outros segmentos sociais, preocupação com a postura/conduta profissional, preconceitos contra grupos específicos e diversidade de objetivos e funções da atividade profissional.

Para deixar mais claro estes aspectos, as RS identificadas nas pesquisas foram organizadas em categorias e seus respectivos elementos identificadores nas pesquisas analisadas, demonstradas no quadro 8 , abaixo.

QUADRO 8. Categorias de RS sobre profissão de EF identificadas com o estado do conhecimento em artigos, teses e dissertações

\section{CATEGORIAS DE RS ELEMENTOS IDENTIFICADORES NAS SOBRE A PROFISSÃO DE PESQUISAS ANALISADAS EF}

Diversidade de objetivos e Saúde, lucro, atividade física, formação, esporte, funções da atividade animador, educador. profissional.

Críticas à formação Valorização das experiências como atleta/praticante acadêmica. e na prática profissional, incentivo de técnicos e professores, EF não foi primeira opção de curso superior. 


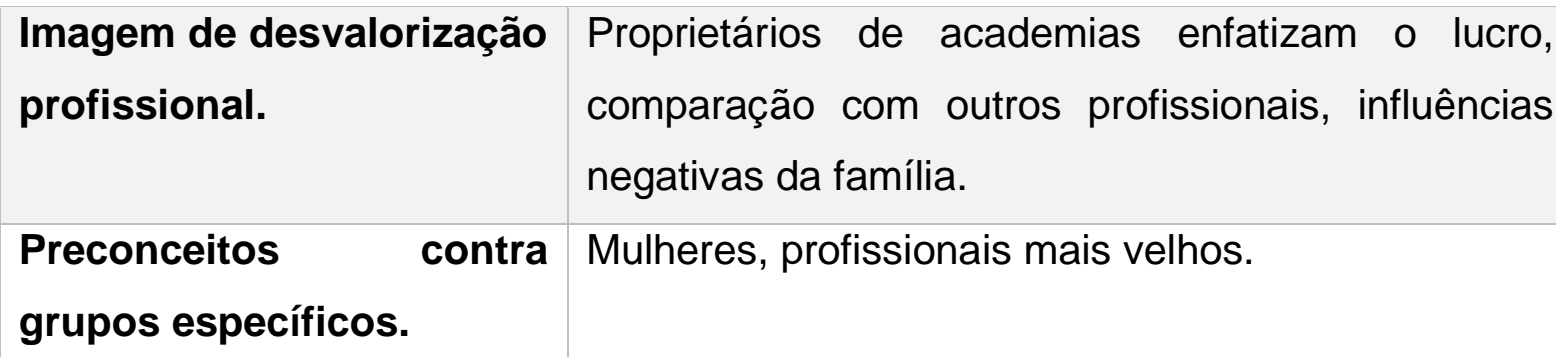

Preocupação com a Autocrítica, ética, responsabilidade, dedicação e postura/conduta comprometimento com a ação pedagógica.

profissional.

Valorização por outros Gestores e usuários do sistema de saúde. segmentos sociais.

Comunidade rural.

Fonte: os autores.

Estes dados mostram que as RS direcionam para uma profissão com um campo de atuação bem amplo, indo ao encontro da diversidade de campos de atuação e sujeitos de pesquisa, conforme apresentado acima sobre as características dos estudos identificados.

Outro aspecto que fica evidenciado nas RS da profissão de EF é o da crítica que os próprios profissionais tecem sobre a sua formação acadêmica. Esta crítica está pautada no processo de construção da identidade profissional da área, que é marcada, desde o início, com obstáculos para o seu reconhecimento social.

Estes aspectos negativos sobre a profissão ainda são reforçados por alguns preconceitos que ainda persistem em nossa sociedade e influenciam a prática profissional da $E F$, como é o caso dos preconceitos de gênero e idade.

Esta RS, pode-se dizer, negativa da profissão leva a uma outra característica, demonstrada nas pesquisas, que é a busca e a preocupação com a postura/conduta profissional. Na maioria dos estudos analisados são apresentados sugestões e direcionamentos para a melhoria e atualização, tanto da formação quanto da intervenção do profissional de EF. Assim, fica evidente que os estudos sobre as RS da profissão de EF estão pautados para um avanço e para uma imagem mais 
valorizada da área. E esta melhoria da imagem profissional passa pela mídia, especialmente a internet.

Em contrapartida, existe uma valorização da profissão por outros segmentos sociais, conforme mostraram algumas pesquisas analisadas (KONRATH, 2015; MONTEIRO, 2016). Portanto, é notório que a área de EF também possui um reconhecimento social, mas na perspectiva dos próprios profissionais ainda não é suficiente, principalmente quando comparada com outras profissões mais tradicionais, principalmente da área da saúde, como os médicos ou fisioterapeutas, ou ainda, com ex-atletas que acabam atuando no ramo do esporte ou do fitness, por exemplo.

Além destas pesquisas que foram analisadas, outros estudos também demonstram esta percepção de desvalorização da profissão de EF. Esta percepção de desvalorização está presente desde a carreira docente, em todos os níveis de ensino (BORCK; OLIVEIRA; FRIZZO, 2019; FAVATTO et al., 2019; MARQUES et al., 2015; MELLO et al., 2012), passando pela formação acadêmica e científica (SOUZA; LUZZI; PEREIRA, 2010) e academias de ginástica (SILVA; SANTOS; ARAÚJO, 2016), apenas para citar algumas áreas.

\section{CONSIDERAÇÕES FINAIS}

A luta pela equiparação do professor de ginástica aos demais professores, a busca pela obrigatoriedade da EF nas escolas, o reconhecimento como uma disciplina acadêmica, a disputa no mercado com leigos e outros profissionais, são alguns dos obstáculos enfrentados durante a história acadêmica e profissional da área e que, com diferentes níveis, ainda existem.

A constituição da área foi marcada pelas influências dos médicos, militares, esportistas e intelectuais. Contudo, a contribuição mais significativa foi a dos médicos e militares que deram à educação física um caráter utilitário, eugênico e higiênico. As décadas de 30 e 40 marcaram um momento de luta por seu reconhecimento social. A obrigatoriedade da educação física no sistema escolar e a exigência do currículo 
mínimo para os cursos de graduação foram fundamentais para a regulamentação e organização da área. (SOUZA NETO et al., 2004).

Essa tendência de uma RS da profissão de EF baseada na desvalorização mostra a necessidade em entender também como a internet, devido ao seu papel essencial na comunicação, está representando esta profissão. Como nos lembra Lahlou (2005), o processo de constituição das RS também acontece por meio das interações dos indivíduos com a mídia.

Estes aspectos das RS, apresentados nas categorias, demonstram uma amplitude da atuação dos profissionais que pode influenciar como a sociedade e a própria mídia, particularmente na internet, constroem as RS sobre a profissão de EF. Este leque de possibilidades leva a atuação dos profissionais para diferentes grupos sociais, com diferentes objetivos e perspectivas, como a prática de esportes, lazer, saúde e as práticas educacionais. Cada ambiente desses leva a um grupo específico com suas demandas, modos de vida e construções discursivas.

Consequentemente, contribuindo para a construção das representações sociais sobre a profissão de EF. E como nos ensina Moscovici (1961-2012) a construção da realidade está entrelaçada com a comunicação e a socialização do saber. Por conseguinte, este processo comunicativo e de socialização do saber é realizado pelos meios de comunicação, particularmente a internet.

Moscovici (2013) alerta para o equívoco em reduzir o social às relações interpessoais ou intersubjetivas e negar a especificidade do indivíduo fazendo desaparecer as distinções. Assim, Moscovici explica a nossa tentação de incorporarmos os aspectos do mundo social no mundo da experiência individual.

Do mesmo modo quando Moscovici (2013) fala da sua repulsa entre o dualismo ente o mundo individual e social, a EF deveria também se posicionar desta forma, visto que é uma área dependente de conhecimentos e práticas inter e multidisciplinares, ou seja, lida tanto com processos íntimos, de natureza fisiológica como com a relação entre pessoas e grupos. 
E com esta perspectiva integradora da TRS, de compreensão sobre os fenômenos sociais, mostra-se necessária uma interpretação mais ampla da Educação Física, no sentido de identificar aspectos marcantes e que ficam em evidência nas RS sobre a profissão.

\section{REFERÊNCIAS}

ALMEIDA, A. M. DE O. Abordagem societal das representações sociais. Sociedade e Estado, Brasília, v. 24, n. 3, p. 713-737, dez. 2009.

ALMEIDA, L. T. P. de. Docência superior e representações sociais no campo da educação física escolar: narrativas de professores do curso de licenciatura. 2017. Tese (Doutorado em educação). Universidade Estácio de Sá, Rio de janeiro, 2017. Disponível em: https://catalogodeteses.capes.gov.br/catalogo-teses/\#!/. Acesso em: 20 abr. 2020.

ARAUJO, M. S. Os sentidos das representações sociais sobre a intervenção do profissional de educação física na estratégia saúde da família. 2015. Dissertação (Mestrado em educação física). Universidade Estadual de Londrina, Londrina, 2015. Disponível em: https://catalogodeteses.capes.gov.br/catalogo-teses/\#!/. Acesso em: 9 abr. 2020.

BORCK, D. T.; OLIVEIRA, I. B. DE; FRIZZO, G. F. E. Professor de Educação Física do $1^{\circ}$ ao $5^{\circ}$ ano da RMEPel: perfil, sentimentos de valorização e formação continuada. Revista Thema, [S. I.], v. 16, n. 1, p. 83-95, 1 maio 2019.

COELHO FILHO, C. A. A. O discurso do profissional de ginástica em grandes academias no Rio de Janeiro. 1998. Dissertação. (Mestrado em educação física). Universidade Gama Filho, Rio de Janeiro, 1998. Disponível em: http://www.nuteses.temp.ufu.br/tde_busca/processapesquisa.php?pesqexecutada=2 \&id=264\&listadetalhes\%5b\%5d=264\&processar=processar. Acesso em: 12 abr. 2020. 
COELHO FILHO, C. A. A. O discurso do profissional de ginástica em academia no Rio de Janeiro. Movimento (ESEFID/UFRGS), v. 6, n. 12, p. 14-25, 2000.

DURKHEIM, É. As regras do método sociológico. São Paulo: Cia. Editora Nacional, 1971.

DURKHEIM, É. Representações Individuais e Representações Coletivas. In: DURKHEIM, É. Sociologia e Filosofia. São Paulo: Edipro, 2015, p. 25-50.

FAVATTO, N. C. et al. Motivos para abandono e permanência na carreira docente em educação física. Revista Brasileira de Ciências do Esporte, v. 41, n. 2, p. 127-134, jun. 2019.

GUTH, F. A. B. Representações sociais de licenciandos em ciências biológicas e educação física da UFMT, sobre o futuro do trabalho docente: um estudo sobre razões para ser professor, atividades docentes atuais e futuras e do que dependerá o trabalho do professor. 2008. Dissertação (Mestrado em educação). Universidade Federal de Mato Grosso, Cuiabá, 2008. Disponível em: http://www.biblioteca.ufmt.br/pergamum/biblioteca/index.php. Acesso em: 15 abr. 2020.

HONORATO, I. C. R. As representações sociais dos acadêmicos do curso de licenciatura em educação física sobre o que é ser professor. 2017. Tese (Doutorado em Educação). Universidade Estadual de Ponta Grossa, Ponta Grossa, 2017. Disponível em: https://catalogodeteses.capes.gov.br/catalogo-teses/\#!/. Acesso em: 9 abr. 2020.

KONRATH, M. Para além do "cara que joga bola": políticas públicas de saúde e o profissional de educação física. 2015. Tese (Doutorado em ciências sociais). Universidade do Vale do Rio Dos Sinos, São Leopoldo, 2015. Disponível em: https://catalogodeteses.capes.gov.br/catalogo-teses/\#!/. Acesso em: 20 abr. 2020. 
LAHLOU, S. Tecnologia e cultura das representações sociais. In: Oliveira, D.C.; Campos, P. H. Representações Sociais: uma teoria sem fronteiras. Rio de Janeiro: Museu da República, p. 99-108, 2005.

MARQUES, M. N. et al. Os desafios do cotidiano educacional: o caso da educação física. Roteiro, Joaçaba, v. 40, n. 1, p. 187-206, jan./jun. 2015.

MELLO, A. DA S. et al. Representações sociais sobre a educação física na educação infantil. Revista da Educação Física / UEM, Maringá, v. 23, n. 3, p. 443-455, set. 2012.

MONTEIRO, S. R. A. F. Representações sociais, docência e práticas em educação física nas escolas rurais/campo/roça do município de Cunha, SP. 2016. Dissertação. (Mestrado Profissional em Educação). Universidade de Taubaté, Taubaté, 2016. Disponível em: https://catalogodeteses.capes.gov.br/catalogoteses/\#!/. Acesso em: 8 abr. 2020.

MOROSINI, M. C.; FERNANDES, C. M. B. Estado do Conhecimento: conceitos, finalidades e interlocuções. Educação Por Escrito, Porto Alegre, v. 5, n. 2, p. 154164, jul.-dezc. 2014.

MOSCOVICl, S. A Psicanálise, sua imagem e seu público. Petrópolis: Editora Vozes, 2012.

MOSCOVICl, S. Prefácio. In: Guareschi, Pedrinho; Jovchelovitch. Textos em representações sociais. Petrópolis, RJ: Vozes, 2013, p. 07-15.

OLIVEIRA, G. A. S. de. Representações sociais de mulheres técnicas sobre o comando de equipes esportivas de alto nível. 2002. Dissertação. (Mestrado em Educação Física) - Universidade Gama Filho, Rio de Janeiro, 2002. Disponível em: http://www.nuteses.temp.ufu.br/tde_busca/processaPesquisa.php?pesqExecutada=2 \&id=149\&listaDetalhes\%5B\%5D=149\&processar=Processar. Acesso em: 8 abr. 2020 . 
OSÓRIO, Y.; ASSIS, M. R.; PEREIRA, G. A representação social de estudantes de educação física sobre o campo profissional. Pensar a Prática, Goiânia, v. 16, n. 2, p. 320618, abr./jun. 2013.

PRONI, M. W. Universidade, profissão Educação Física e o mercado de trabalho. Motriz: Revista de Educação Física, Rio Claro, v. 16, n. 3, p. 788-798, jul./set. 2010.

ROMANOWSKI, J. P.; ENS, R. T. AS PESQUISAS DENOMINADAS DO TIPO "ESTADO DA ARTE" EM EDUCAÇÃO. Diálogo Educacional, Curitiba, v. 6, n.19, p.37-50, set./dez. 2006.

SÁ, C.P. A construção do objeto de pesquisa em Representações Sociais. Rio de Janeiro: EDUERJ, 1998.

SILVA, F. I. C.; SANTOS, A. M. L.; ARAÚJO, D. M. E. Perfil profissional do personal trainer atuante em academias de Teresina-PI. RBPFEX - Revista Brasileira de Prescrição e Fisiologia do Exercício, São Paulo, v. 10, n. 61, p. 634-644, set./out. 2016.

SILVA, M. C. da. $O$ mundo à beira da piscina: as representações sociais de técnicos de natação sobre sua formação profissional. 2017. Tese (Doutorado em educação física). Universidade Estadual de Londrina, Londrina, 2017. Disponível em: https://catalogodeteses.capes.gov.br/catalogo-teses/\#!/. Acesso em: 9 abr. 2020.

SOUSA, D. P.; PAULA, E. F.; OLIVEIRA JR, C. R.; ANTUNES, A.C. Apropriação da teoria das representações sociais pelo campo acadêmico/científico da educação física no Brasil: o estado do conhecimento (2004-2016). Pensar a Prática, Goiânia, v. 21, n. 4, out./dez. 2018.

SOUZA, E. R.; LUZZI, A.; PEREIRA, B. O fordismo acadêmico na educação física. Revista Brasileira de Ciências do Esporte, Florianópolis, v. 32, n. 2-4, p. 43-57, dez. 2010. 
SOUZA NETO, S. et al. A formação do profissional de educação física no Brasil: uma história sob a perspectiva da legislação federal no século XX. Revista Brasileira de Ciências do Esporte, Campinas, v. 25, n. 2, p. 113-128, jan. 2004.

TOLEDO, A. S. As representações sociais do profissional de educação física construídas por profissionais de saúde. 2003. Dissertação. (Mestrado em educação física). Universidade Católica de Brasília, Brasília, 2003. Disponível em: https://pergamum.ucb.br:8443/pergamum/biblioteca/index.php. Acesso em: 14 abr. 2020.

TRIANI, F. S. et al. As representações sociais de bacharelandos sobre ser profissional de educação física. Journal of Physical Education, Maringá, v. 30, p. 01-09, 2019.

\section{APÊNDICE - REFERÊNCIAS DE NOTA DE RODAPÉ}

4. ENDEREÇO: https://catalogodeteses.capes.gov.br/catalogo-teses/\#!/

5. ENDEREÇO: http://www.periodicos.capes.gov.br/

6. Alerta-se para o fato desta pesquisa também ter sido publicada em artigo (Revista Movimento, 2000), que será analisado na sequência das teses e dissertações.

7. Este artigo fundamenta-se na dissertação de mestrado com o mesmo título, analisada acima, de acordo com o Quadro 3.

8. Devido aos estudos de Coelho Filho (1998; 2000) terem o mesmo teor (resultados e conclusão), diferenciando-se pelo fato de o artigo ser resultado da dissertação de mestrado, a discussão e interpretação levará em consideração os dois estudos como sendo somente um.

9. consiste em se pedir aos sujeitos que, a partir de um termo indutor (normalmente, o próprio rótulo verbal que designa o objeto da representação) apresentado pelo pesquisador, digam as palavras ou expressões que lhes tenham vindo imediatamente à lembrança. (SÁ, 1996, p. 115). 
Enviado: Novembro, 2020.

Aprovado: Novembro, 2020. 